\title{
GIDE, KAFKA, WOOLF. ILUMINACIÓN DE SU VIDA Y OBRA A TRAVÉS DE LOS DIARIOS
}

\author{
Guillermo AGUIRRE MARTÍNEZ \\ Universidad Complutense de Madrid \\ guillermo-aguirre@hotmail.com
}

\section{Introducción. El origen}

$\mathrm{P}$ ese a que novela, poesía y drama conforman los tres géneros literarios por excelencia, los diarios, lejos de pertenecer a un escalón inferior en su valía estética, pertenecen a esa otra tipología de escritura que en ocasiones alcanza una belleza que en nada tiene que desmerecer respecto de algunas de las mejores obras literarias que se hayan escrito. Conforme a esto, podemos hallar poesía en cualquier texto estéticamente desarrollado. De este modo, resulta posible elevar ciertas cartas, deliciosas conversaciones o, en el caso que aquí concierne, fascinantes diarios, a la altura de género literario. Por desgracia, muchos son los autores consagrados que no ponen el mismo empeño en este tipo de escritos que en otros usualmente considerados más serios. Se puede, sin embargo, citar una gran cantidad de diarios que merecen las mismas oportunidades de ser leídos que muchos otros clásicos de las letras. Es el caso de los famosos diarios de guerra de Junger, el Diario íntimo de Novalis, el de juventud de Rilke, o el mismo Diario de André Gide.

En ciertas ocasiones, estas obras cobran, además, una especial importancia debido a la carga autoanalítica que los autores depositan sobre sus páginas. En estos casos, la psicología de quien los escribe se transfiere de modo evidente y lo anotado sobrepasa a su vez el marco íntimo limitando así con aspectos relativos a las ciencias humanas. Todo lo que se pierde en belleza se recuperará mediante el conocimiento que aportan sobre la personalidad del autor. Un ejemplo significativo lo encontramos en Kafka.

No muy diferentes en su rol a los del autor checo, los Diarios de Virginia Woolf cobran su verdadero interés de modo indirecto, una vez que su mano es la misma que la que escribió Las olas o La señora Dalloway, aspecto que les dota de relieve y, sin duda, 
de sumo interés. Por otra parte, merecen especial atención debido a la diversidad de personalidades interesantes que aparecen entre sus líneas.

Cada uno de ellos está redactado conforme a un fin claramente diferente: belleza, autoanálisis y, en el caso de Virginia Woolf, un cierta dosis de ambos aspectos además de por el placer de realizarlos y, posiblemente, por seguir con la tradición que existía antaño en las familias inglesas consistente en elaborar unos "diarios de familia" cuyo fin último consistía en traspasarlos de padres a hijos, de generación en generación, y de este modo dejar por escrito aquello que el poeta William Butler Yeats denominó «la gran memoria».

\section{1. André Gide}

El Diario de André Gide es paradigmático debido a que está escrito como si de una realización estética ordinaria se tratase. En él no vamos a encontrar frases incompletas, tachaduras o despreocupación formal. Es una obra tan acabada y de tanto valor literario como lo pueden ser sus novelas.

Desde el punto de vista de quien estudie la personalidad del autor podría parecer que estos escritos autobiográficos muestran, debido a su cuidada elaboración, menos interés que si se nos presentasen de modo más espontáneo y, por tanto, descuidado; sin embargo, este esmero constituye precisamente una de las causas por las que el Diario de Gide se eleva por encima de muchos otros anales concebidos igualmente con el propósito de salir a la luz pública. La razón es que toda la obra del autor francés, según él mismo señaló repetidamente, tuvo como motivación extrema la necesidad de darse a conocer tal cual es, sin tapujos, reafirmando su personalidad en todas sus facetas vitales, especialmente aquéllas relativas a la moral. Este objetivo, tema principal y común en la mayoría de sus escritos, cobra importancia especialmente en esta obra, paradigma de veracidad. Apenas deja lugar a sospechas en cuanto a su sinceridad, pues raro es dejar de encontrar una y otra vez al descubierto y sin velo disuasivo pasajes manifiestamente controvertidos, ya sean los referidos a su identidad sexual, a su ideología política o a sus relaciones con la Iglesia. En ningún caso tiene el autor intención de proteger su persona, «No escribo estas memorias para defenderme» (Gide, 1951: 229). Simplemente expone la realidad tal y como él la observa. Él mismo se encarga de ser tanto su propio juez como su verdugo, llegando en ocasiones hasta el auto-tormento, aspecto que contrasta de manera patente con cualquiera de sus novelas, en las que sin lugar a dudas se muestra más condescendiente con su forma de actuar o incluso se presenta como abogado de posturas que él mismo condena o al menos se cuestiona en el Diario. 
Llegado a este punto, si aún se duda de su sinceridad hacia él mismo y hacia el lector, existe un valioso documento que confirma los hechos narrados por André Gide. Se trata de los Cahiers de la Petite Dame, cuya elaboración la llevó en secreto, al menos en un primer momento, Théo van Rysselberghe, íntima amiga del autor. Gide llegaría a conocer la existencia de estas anotaciones, sin embargo, y según testimonio de todas aquellas personas que convivieron junto al autor, en nada varió la forma de comportarse ante su amiga respecto de aquella época en que aún no era consciente de la existencia de estos escritos. Su naturalidad no dejaba lugar a dudas.

Retomando de nuevo lo concerniente al Diario, la fecha en la que Gide tomó la decisión de publicarlo es de difícil precisión, pues se trata de una posibilidad que solo fue cobrando fuerza con el paso de los años. Los Diarios no surgen ni se desarrollan de manera espontánea; a lo largo de la primera década del siglo se va a observar en ellos una evolución hacia una mayor conciencia a la hora de redactarlos. Gide intuía que ya no era él el único destinatario de cuanto anotaba ${ }^{1}$, sino que también lo era un futuro público por el que debía escribir con la misma sinceridad que la demostrada hasta esos momentos, preocupándose, además, por un mayor cuidado formal. Una de las consecuencias que provocó este cambio consistió en que a partir de los años veinte sus anotaciones se volvieron menos íntimas, abarcando temas más generales con el fin de no «vivre et mourir devant un miroir», parafraseando a Baudelaire. A partir de entonces, las referencias a hechos personales concretos, a sus relaciones íntimas, se reducen, pero, a cambio, aparecen temas de más amplio alcance como pueden ser cuestiones de orden político o religioso. Un ejemplo de cada etapa se puede observar a través de las siguientes citas. La primera data de julio de 1888 y se corresponde con claridad con el periodo en que prevalece lo íntimo y privado: «Estoy loco, estoy loco, forjo quimeras y luego me asustan [...] No temas; cree nada más [...] Dejadme; no sabéis lo que sufre un corazón que no sabe su camino» (Gide, 1951: 65).

\section{2. Franz Kafka}

Jamás imaginó Kafka, al menos no sin pavor, que una sola página de sus diarios se podría llegar a publicar algún día. En la época en que Kafka comenzó estos cuadernos tenía veintisiete años. A pesar de lo mucho que había escrito, la proporción de lo conservado respecto de aquello arrojado a la estufa resultaba brutal y desalentadora. Por poner un ejemplo, La condena, cuyo texto lo redactó de forma íntegra en las páginas del diario, le supuso al autor checo la culminación de años y años

\footnotetext{
${ }^{1}$ Sobre este aspecto Gide afirma: «Desde hace tiempo este cuaderno ha dejado de ser lo que debería ser: un confidente íntimo. La perspectiva de una publicación, aunque sea parcial, de mi diario, como apéndice a mis Obras completas, ha falseado su sentido; y también fatiga o pereza o dislocación de mi vida, temor a que se pierda lo que habría debido verter en libros o artículos» (Gide, 1951: 335).
} 
de trabajo en los que había intentado, sin éxito, la elaboración de un texto mediante un único rapto de escritura sin interrupción alguna de por medio. Antes de que llegase esta narración, Kafka había destruido no cientos, sino miles de hojas manuscritas de las que tan solo se ha conservado una breve y fragmentada selección. El autor era muy consciente de que necesitaba algún tipo de cuaderno al que aferrarse para no sentir que todo lo realizado resultaba absolutamente en balde e infructuoso, de ahí la necesidad de comenzar a escribir un diario así como la razón de que optase por utilizarlo a modo de cajón de sastre. Por este motivo, por el simple hecho de anotar meros datos o estados de ánimo, lograba aliviar un tanto su ansiedad literaria. En otras ocasiones, en las que se le ocurría comenzar alguna historia, aprovechaba esas mismas páginas para continuar lo que podría llegar a ser un buen relato. Son numerosas las referencias que el autor hace respecto a la necesidad de continuar llenando las páginas de sus conocidos cuadernos de tapas marrones: « ¿Desde hoy no dejar el diario! ¡Escribir con regularidad! ¡No rendirse! Aunque no haya redención, voy a ser en todo momento digno de ella» (Kafka, 1937: 154).

Así, en el caso de Kafka, la escritura del diario consistía en un acto supletorio frente a aquel otro primordial y puramente creativo, motivo por el que en aquellas ocasiones en que conseguía dar rienda suelta a su creatividad, no necesitaba a su vez redactar unas líneas en el diario, pues su función ya no le era necesaria salvo que quisiese expresar su alegría y alivio por haber podido trabajar con satisfacción. Un ejemplo de lo anotado en un día infructuoso lo podemos observar en esta cita de mayo de 1913: «Se ha hecho muy necesario llevar un diario nuevamente. Mi cabeza insegura, F., el derrumbamiento en la oficina, la imposibilidad física de escribir y la íntima necesidad de hacerlo» (Kafka, 1937: 189). Por el contrario, tras lograr engendrar una narración el día veintiséis de marzo de 1912, utilizará su cuaderno solo para dejar patente su orgullo por cuanto acaba de crear: «Simplemente, no dar un valor excesivo a lo que he escrito, porque me resultaría inalcanzable lo que he de escribir» (Kafka, 1937: 169).

Por lo tanto, más que un cuaderno al uso en el que se informa sobre las actividades cotidianas, su diario fundamenta su valor e interés debido a la gran cantidad de esbozos literarios que en su interior hallamos. Como se ha señalado en el párrafo anterior, su función supletoria es la causa de que a menudo el autor se centre más en plasmar un carrusel de ideas que en relatar con orden y detenimiento la actividad del día.

Respecto al hecho de que Kafka llegase a considerar en algún momento la posibilidad de publicar sus diarios, parece evidente que jamás se le pasó por la cabeza y que, de haber sido él quien hubiese tenido que decidir al respecto, sus páginas no 
habrían llegado hasta nosotros. El material que estos cuadernos contienen resulta tan personal y revelador, sobre todo en alguien tan hermético como Kafka, que el escritor los mantenía siempre fuera del alcance de su familia o sus amigos, más si cabe dados los frecuentes reproches que se inflinge a sí mismo, a su familia y a su entorno en general, desvelando una personalidad configurada a partir de ciertos rasgos obsesivos demasiado comprometedores como para quedar al alcance de cualquiera.

Por último, hay que comentar que su amigo y biógrafo Max Brod, afirma sin recato alguno que todo el mérito de que Kafka hubiese llegado a escribir sus Diarios hay que concedérselo a él mismo, al propio $B^{2}{ }^{2}$. Pese a tal presunción, a Brod hay que cederle el mérito de que estos Diarios viesen, en contra de los deseos del novelista, la luz pública. Mucho se ha comentado sobre esta controvertida cuestión que engloba aspectos éticos y estéticos y que se alejan del ámbito de estudio de estas páginas.

\section{3. Virginia Woolf}

Los Diarios de Virginia Woolf en un principio no estuvieron destinados a ser editados. La escritora londinense los utilizaba con el fin de poseer un refugio propio donde poder anotar todo lo que le viniese en gana de la forma que quisiese. En palabras de la autora, redactaba estos cuadernos «para exorcizar mis demonios» (Woolf, 1941a: 26). En ellos no tenía que reescribir cuanto le disgustase, pudiendo dejarlos de lado durante unos cuantos días sin que esto le produjese graves quebraderos de cabeza, acción impensable cuando trabajaba en sus novelas. Frente a esta escritura libre, sus obras serias usualmente se tornaban en causa de doloroso tormento, especialmente aquellas cuyo argumento contenía un fuerte componente introspectivo, tal y como observamos, por ejemplo, en Las olas. En estos últimos casos, su trabajo le resultaba tan agotador que optó casi toda su vida por obligarse a que a una obra de gran carga emocional le siguiese otra de contenido y redacción más plácida, como puede ser Una habitación propia, ensayo en el que defiende ciertas condiciones básicas de cara a que las escritoras puedan desarrollar su trabajo con la tranquilidad que demanda la creación literaria. Por todo ello, el poseer un espacio donde poder garabatear cualquier banalidad sin juzgarse de continuo le confería a sus diarios una capacidad regeneradora necesaria de cara a mantener en equilibrio su naturaleza creativa.

\footnotetext{
2 «Lo impulsaba, lo empujaba, claro que no directamente, sino empleando siempre nuevos medios y rodeos; evité que su talento volviera a caer en punto muerto. Había épocas en que me lo agradecía. A menudo le resultaba cargante mi estímulo y concluía por mandarlo al diablo, pero no me importaba. Me importaba la ayuda, aun contra la voluntad del amigo. El que Franz haya llegado a la idea de escribir Diarios íntimos lo anoto como mérito mío. Sus cuadernos brotaban inmediatamente de nuestras breves anotaciones de viaje y eran, en cierto modo, su continuación» (Brod, 1937: 104).
} 
Virginia Woolf, en un principio, no tenía pensado que estas hojas descuidadas, repletas de ideas inconexas, poco trabajadas y tan personales, pudiesen y mereciesen ser editadas. Solo en una época de madurez, cuando ya había logrado un gran éxito de ventas acompañado del consiguiente reconocimiento público, señaló la posibilidad de que de entre todos estos folios encuadernados pudiese extraerse al menos un volumen con cierto valor tanto literario como biográfico ${ }^{3}$.

Consideraba que el momento más adecuado para hacer la selección de los textos llegaría cuando fuese una anciana sin apenas ganas de escribir. A causa de su prematura muerte, dicha idea nunca pudo ser realizada tal y como deseó. Pese a todo, su marido Leonard se encargó de llevar a cabo este proceso una vez fallecida la escritora. Leonard se dedicó a leer y releer sus diarios y a entresacar de ellos los contenidos que pudiesen aportar información valiosa o que tuviesen cierta calidad literaria. Los primeros volúmenes publicados no eran tan extensos como los que se editan hoy en día. En un primer momento, se hizo una selección más rigurosa tanto por respeto a la intimidad de Virginia Woolf como debido a que estas páginas contenían multitud de descripciones y anotaciones referentes a personas que aún permanecían vivas en el momento de su edición. Según comenta su biógrafo Quentin Bell, muchos de estos comentarios eran manifiestamente ofensivos: «He encontrado cosas muy descorteses en su diario». A continuación, cuando le preguntan si esas anotaciones encontradas son falsedades, responde «No [...] Todo es rigurosamente cierto... desgraciadamente» (Forrester, 1973: 82). De este modo, permanecen aún hoy inéditos muchos de esos pensamientos críticos y ofensivos, así como tantas y tantas páginas que no aportan nada acerca de su vida $\mathrm{u}$ obra.

Virginia Woolf consideraba que uno de los propósitos del diario era el de registrar los pequeños momentos que trazan el recorrido de la existencia. A menudo se imaginaba que pasados unos años disfrutaría leyendo unas páginas sentada en su sillón, o se dedicaba a fantasear con la reacción que le provocarían determinados pasajes, especialmente los más exacerbados. De ello queda constancia en una entrada de los Diarios redactada en una ocasión en que reflexionó acerca de la posibilidad de dejar de escribirlos: «Me quiero imaginar a la vieja Virginia Woolf poniéndose las gafas para leer marzo de 1920, deseando decididamente que continúe. ¡Felicidades! mi querido fantasma» (Woolf, 1941a: 223).

\footnotetext{
${ }^{3}$ Según registra Woolf en su diario: «Ayer me pregunté qué será de estos diarios. Si muriese, ¿Qué haría Leo con ellos? Se sentiría remiso a quemarlos; no podría publicarlos. Bueno, podría entresacar lo suficiente para hacer un libro, y quemar el resto. Me atrevería a decir que en este diario se contiene un librito, siempre y cuando se puliera un poco el texto. En fin, sólo Dios lo sabe» (Woolf, 2003: 117).
} 
Por último, en febrero de 1927 anota: «¿Para qué otro cuaderno?... ¿Qué propósito tienen?... Los usaré para escribir mis memorias un día de estos» (Woolf, 1941a: 88). Estas supuestas memorias jamás las llegaría a realizar.

\section{El proceso creativo}

Dentro del conjunto de los diarios, nos encontramos con diferentes tipologías, las más comunes de orden interno. Los hay que recogen tan solo las actividades diarias sin realizar apenas algún comentario a modo de ornamento, otros van a dar preponderancia a una exposición de sentimientos y responden a una necesidad de expresar estados de ánimo. En el caso que nos atañe, se da la circunstancia de que los mismos elementos que componen los diarios, las palabras, constituyen también el material con el que van a dar forma a las ideas con las que usualmente trabajan. Por ello, su utilización resulta ideal de cara a ir registrando pensamientos, anécdotas, o cualquier tipo de elemento que pueda ser reutilizado en otra serie de escritos ajenos a estos otros más personales.

En determinados autores, la vida y la obra conforman un todo; una y otra se muestran indisolubles. En estos casos, sin experiencias internas no hay obra e incluso sin obra la vida no tiene sentido alguno. Por este motivo, cualquier frase, cualquier vivencia sin un fin prefijado, va a gozar de la posibilidad de ser volcada sobre una obra posterior. Esto es algo que observaremos en el caso de estos tres autores.

Cada uno, no obstante, tiene su particular método para realizar sus anotaciones. Así, por ejemplo, en los Diarios de Kafka entra cualquier tipo de contenido, desde la anotación de los medicamentos que le interesa tomar o la comida que ha degustado el día anterior, hasta la redacción de un relato de principio a fin. Virginia Woolf, por su parte, obedecía a un plan más metódico o, al menos, su método resultaba menos embrolloso; a cada cuaderno le asignaba una función determinada, quedando uno de ellos dedicado exclusivamente a sus diarios, mientras cualquier otro lo empleaba para tomar notas concernientes a una novela determinada o a una actividad diferente. Pese a esta delimitación previa, todo tipo de ideas o descripciones apuntadas encontraban cabida finalmente en el resto de sus obras de mayor envergadura. Por su parte, en André Gide observamos que el Diario constituye de por sí un libro más dentro del conjunto de su producción, no desmereciendo en nada en cuanto a elaboración y altura de pensamiento de cualquiera de sus otras creaciones. No obstante, los diarios, a su vez, constituirán una fuente inagotable de ideas con las que nutrir el conjunto de su producción. Rizando el rizo, el mismo Diario se compone en ocasiones de otros muchos diarios que el autor solía realizar de manera simultánea. 
Gide, Kafka, Woolf. Iluminación de su vida y obra a través de los diarios

\section{1. André Gide}

El crítico Daniel Moutote afirmaba que el Diario de Gide constituye «La matriz de toda su obra literaria» (Gide, 1951: 23). Para muchos, el Diario es posiblemente el mejor libro del autor, su gran obra, semilla y fruto a un mismo tiempo. Semilla en cuanto que aporta una gran cantidad de datos, recuerdos e ideas que sirven de base a futuros proyectos literarios. Fruto, en tanto que todo ese manantial de reflexiones, anécdotas y apuntes, cobran belleza ya desde el mismo momento en que quedan grabados en el papel. Su estructura resulta así similar a la de una catedral gótica. En ellas, los arcos, soportes y contrafuertes, no solo cumplen la función de aguantar el bello y estilizado cuerpo del conjunto, sino que dichos elementos configuran, por sí mismos, creaciones individuales rebosantes de belleza. Esta estructura o retórica linguística, la representa Gide sin necesidad de revestir los elementos con el fin de embellecerlos, pues con una prosa sencilla logrará hacer del amasijo de ideas que a menudo son los diarios, una obra cuyos elementos nacen ya armonizados y con total coherencia tanto interna como externa dentro del conjunto de su producción. Por ello, el diario no solo se satisface a sí mismo sino que alimentará a su vez futuras creaciones, llegándose incluso al extremo de que se recupere un pasaje anotado en 1889 donde describe en su imaginación el suicidio de un niño, para desarrollarlo, veintisiete años después, en su novela Los monederos falsos. El texto original escrito en el Diario, fechado el once de marzo, es el siguiente: «se puede escribir sobre el suicidio de un niño al que todo el mundo trata como a un niño pero que por su parte se siente hombre -ama, nadie le cree, se burlan de él-, él se exalta, se desespera viendo que no le toman en serio y para imponer a los demás esa seriedad que ellos no quieren otorgarle, se suicida» (Gide, 1951: 74-75). En otras ocasiones se encontrarán incluso anotaciones que son trasvasadas casi literalmente a otras obras. Lo observamos en Los cuadernos de André Walter, Los alimentos terrenales o Amyntas. En lo concerniente a este aspecto, Martin du Gard dice lo siguiente: «No hay ni un minuto de su jornada, ni un momento de sus insomnios, en el que el pensamiento [de Gide] esté vacante, en que el cerebro deje de producir materia para libros» (Gide, 1951: 23). Todo este material es el que irá almacenando en sus diarios.

Resulta preciso comentar que Gide fue pionero en el uso del diario ficticio como recurso literario, demostrando una gran propensión a jugar con la literatura para transformarla en metaliteratura. Respecto a esto, lo apuntado en su Diario el veintitrés de septiembre de 1914 se muestra de especial interés: «[...] empecé un nuevo cuaderno [...] en el que he ido anotando, del todo independientemente de mí mismo, lo que, pensaba, podría suministrar material de mi novela» (Gide, 1951: 200). Esta obra era en concreto Los monederos falsos, y el diario del que habla tomó el nombre de Diario de 
Los monederos falsos, iniciado dos años antes de comenzar a escribir dicha obra, en cuyo argumento, colmo de barroquismo, uno de sus personajes anota en su diario que quiere escribir una novela titulada Los monederos falsos. Otro uso múltiple y similar de los diarios, según lo explica el propio autor ${ }^{4}$, lo llevó a cabo durante el proceso de elaboración de Los cuadernos de André Walter.

De este modo, se observa cómo en el caso de Gide, la vida, la obra, el Diario, y estos diarios en órbita alrededor de cualquiera de sus creaciones, se retroalimentan unos a otros. Continuando con la cita anterior, Gide añade: «pero este nuevo método no vale nada en cuanto los acontecimientos exteriores dejan de predominar sobre la vida íntima» (Gide, 1951: 200). Debido a este aspecto, si el autor quería realizar este tipo de literatura y no dejar de lado su sinceridad, y esto realmente no era una opción sino una imposición en tanto que confería sentido a su vida, no le quedaba otro remedio que ser persona y personaje a un mismo tiempo.

\section{2. Franz Kafka}

En aquellos momentos dedicados a la elaboración de sus diarios Kafka se sentía especialmente cercano a sí mismo. En ellos escribía todo tipo de ideas y vivencias sin orden alguno, con una redacción en ocasiones defectuosa, repleta de borrones, ideas entrecortadas o repetidas; tejiendo, en fin, una maraña de pensamientos entre los que se observan a menudo esbozos de muchos de sus relatos y novelas.

El caos dominaba en estos escritos; las palabras salían a borbotones pareciendo asfixiarse dentro de él y él a su vez necesitaba sacarlas de sí mismo para evitar ese estado de angustia que le atormentaba durante el resto del día. Por lo general, era una vez que su familia ya se había acostado cuando llegaba el momento en que sacaba los cuadernos de su escritorio y expulsaba ${ }^{5}$ todo lo que había estado conteniendo durante el resto de la jornada. Esperaba siempre con ansia esas horas en las que tenía toda la madrugada por delante para realizar con pleno esfuerzo la actividad para la que se sentía llamado a vivir. Una y otra vez Kafka repite la obsesiva idea de aferrarse al diario con todas sus fuerzas una vez que lo comprendía como un medio esencial de supervivencia. Ante la imposibilidad de escribir un texto elaborado, ante la gran cantidad de páginas y páginas destruidas con tremenda insatisfacción, el diario constituía, por lo general, su

\footnotetext{
${ }^{4}$ Palabras de Gide extraídas de sus memorias: «Todavía debía transcurrir más de un año antes de que pudiese consagrarme verdaderamente a ese libro, pero ya había adquirido la costumbre de escribir un diario, por necesidad de dar forma a una confusa agitación interior; y muchas páginas de ese diario han sido transcritas sin cambio en esos Cahiers» (Gide, 1924: 211).

${ }^{5}$ Con estas palabras registró Kafka su experiencia en su diario: «Con motivo de la corrección de pruebas de La condena, anoto todas las relaciones que se han aclarado para mí en la narración. Esto es necesario, porque la narración salió de mí como en un verdadero parto, cubierta de suciedad y de mucosidades, y sólo yo tengo la mano capaz de llegar al cuerpo y deseosa de hacerlo» (Kafka, 1937: 185).
} 
tabla de salvación. Escribir para no morir. Todo el universo literario y personal de Kafka lo encontramos dentro de estos escritos.

Pese al desorden de ideas, los Diarios no conforman sino un filón de donde se extraerán múltiples cuestiones nucleares recogidas en posteriores obras, en tanto que otras tantas quedarían abandonadas de por vida. Encontramos en su interior un buen número de relatos o novelas iniciadas; es el caso de El mundo urbano o de Barullo. Entre otros escritos, han quedado recogidos entre sus páginas detalles de dramas jamás publicados. Cabe indicar que, por el género dramático, Kafka mostró siempre una enorme pasión; interés, según registra en sus notas, surgido desde que entrase en contacto con la compañía de teatro del actor Jizchak Löwy, formada por judíos orientales con una concepción teatral diferente a la conocida en occidente. Estos textos se recitaban en yiddish, lengua por la que Kafka estaba bastante interesado e incluso llegó a manejarse con cierta soltura. Acerca de ello, el autor escribe: «Hoy he empezado a leer ávida y felizmente Historia del judaísmo, de Graetz» (Kafka, 1937: 83). Su reiterado interés en escribir un drama, por otra parte, quedó en una sucesión de intenciones y proyectos frustrados.

Como curiosidad, en los Diarios encontraremos un par de poesías ${ }^{6}$, género por el que Kafka apenas se interesó, del mismo modo que desatendió por completo el arte musical. En palabras de Max Brod, «Kafka, como para nivelar el don especial de su arte musical de la palabra, carecía de verdadero arte musical» (Brod, 1937: 114). El mismo Kafka, a pesar de acudir de vez en cuando a algún cabaret, concierto o recital poético, deja claro en sus Diarios que no tiene predisposición alguna hacia la música: «La música que escucho levanta un muro a mi alrededor» (Kafka, 1937: 118).

Uno de los poemas registrados en los Diarios anuncia el nacimiento de la narración La condena, cuyo texto completo fue redactado una semana más adelante en el cuerpo del diario. Esto ocurrió en septiembre de 1912, cuando, según deja entrever en los Diarios, de sopetón comenzó a escribir de forma incontrolada ${ }^{7}$, actuando como un

\footnotetext{
${ }^{6}$ Traducción del primero de sus poemas. Escrito una semana antes de la redacción de La condena:

Desde el fondo

del cansancio,

subimos con

nuevas fuerzas,

como oscuros caballeros

esperando

que los niños

se extenúen (Kafka, 1937: 319).

${ }^{7}$ Sobre este tipo de escritura ofrecemos unos textos de C. G. Jung: «[Existen] otras clases de obras de arte que afluyen más o menos completas a la pluma del autor. Estas obras se imponen literalmente al autor, toman posesión en cierto modo de su mano, su pluma escribe cosas que su espíritu contempla con asombro. La obra trae consigo su forma; lo que el autor quiere añadirle es rechazado, lo que él desdeña se le impone. Su conciencia contempla el fenómeno atónita y vacía, mientras se ve inundada por un torrente de ideas e imágenes que su intención jamás ha creado y que su voluntad jamás habría querido producir.
} 
mero amanuense que graba en el papel lo que le es dictado por alguien desconocido. Según relata por carta a Felice Bauer, el autor quería describir a un joven que ve desde su ventana a una multitud acercándose hacia él, sin embargo pronto el relato tomó sus propias determinaciones y se le fue de las manos. Una vez finalizado el relato, lo contempló con satisfacción, describiendo con felicidad su experiencia: «Esta narración, La condena, la he escrito de un tirón, durante la noche del 22 al 23, entre las diez de la noche y las seis de la mañana» (Kafka, 1937: 182). Al día siguiente no realizó ninguna inscripción, pero dos días más tarde, ya sereno y descansado, abrió su cuaderno con estas palabras: «Me he mantenido apartado por la violencia de la actividad de escribir [...] Esta noche me he arrancado violentamente el deseo de escribir» (Kafka, 1937: 183). A continuación, unas líneas más abajo, escribió la copia en limpio de la narración El fogonero.

No se trata, por tanto, de un simple diario. Más bien puede decirse que el cuaderno al que se acercaba cada noche era potencialmente, como así ocurriría en multitud de ocasiones, un espacio susceptible de trascender su finalidad primigenia y pasar a dar lugar a unas páginas cuyo contenido podía llegar a configurar alguno de los grandes textos de la narrativa universal. El carácter indiscernible entre sus escritos publicables y sus escritos íntimos, aparece mencionado ya en la conocida biografía que Max Brod realizase sobre su amigo ${ }^{8}$.

Con renuencia tendrá que reconocer que en todo ello habla su sí-mismo, que su naturaleza más íntima se revela a sí misma y proclama en alta voz lo que él jamás le habría confiado a su lengua. Sólo puede obedecer y seguir ese impulso, aparentemente extraño a él, sintiendo que su obra es más grande que él, por lo que ejerce un dominio al que no puede oponerse. No es idéntico con el proceso de creación artística; es consciente de que se sitúa por debajo de su obra, o al menos a su lado, como una segunda persona que se viera abocada a girar en la órbita de una voluntad ajena a ella [...] Esta oposición ya la percibió Schiller. Trató de abarcarla con los conceptos de sentimental e ingenuo [...].

Las pruebas pueden ser de naturaleza directa o indirecta. Pruebas directas habría en los casos en los que el autor dice, abierta o encubiertamente, más de lo que cree decir, más de lo que él mismo percibe. Tendríamos pruebas indirectas allí donde, detrás de una aparente libertad de producción, se detecta un "deber" más alto que manifestase imperioso sus exigencias cuando se renunciara arbitrariamente a la actividad creadora, o donde surgieran de inmediato severas complicaciones psíquicas en el momento de interrumpir involuntariamente la producción artística.

El impulso creador llega a acaparar para sí todo lo humano, incluso a expensas de su salud y de la felicidad normal del ser humano. La obra que late en el artista antes de nacer es una fuerza de la naturaleza que se impone, bien con tiránica violencia, o con esa argucia sutil del fin natural, sin reparar en el bienestar o en el dolor del ser humano sometido al ansia creadora...

Cabría esperar extrañeza de forma e imagen, pensamientos que sólo pudieran aprehenderse como intuiciones, un lenguaje cargado de significado cuyas expresiones tuvieran el valor de auténticos símbolos, ya que expresan del mejor modo posible cosas desconocidas y constituyen puentes que se tienden hacia una orilla invisible» (Jung, 1995: 64-67).

${ }^{8}$ «Para Kafka, los diarios no tienen sólo una importancia autobiográfica; en medio de comentarios de índole personal están los trozos que recogió luego en su primer libro, y aun muchos de esos trozos, que publicó el mismo, no se pueden diferenciar, por su sustancia, de las anotaciones del diario; no sabemos por qué consideró el autor publicables los unos y retuvo los otros» (Brod, 1937: 105). 
Gide, Kafka, Woolf. Iluminación de su vida y obra a través de los diarios

\section{3. Virginia Woolf}

Para todas aquellas personas que tuvieron relación con Virginia Woolf, una de sus características principales era la de estar siempre con la mente en movimiento, lo que a ella le producía cierto orgullo. Esa imaginación fácil era su arma frente a una realidad que tan poco interés podía ofrecerle si no se le mostraba envuelta con un manto de fantasía. De acuerdo con esto último, no es de extrañar que sus periodos de mayor depresión se produjesen una vez concluida alguna de sus obras. Al constante miedo a la crítica se unía el temor de la vuelta a la realidad, siempre más aburrida que la ensoñación, «Voy a dejar constancia de mi regreso a la vida, es decir, a escribir, por el medio de comenzar un nuevo libro» (Woolf, 2003: 201). Otra entrada de su diario de 1928 alude a que «soñar es con frecuencia mucho más evocador que pensar» (Woolf, 1941a: 119).

Virginia Woolf, por lo común, solía dedicar buena parte de sus cuadernos a describir ambientes y sobre todo personas que le habían llamado la atención. En gran cantidad de ocasiones no constituían meras notas realistas, sino que, partiendo de éstas, comenzaba a fantasear sobre multitud de aspectos. El ejemplo extraído a continuación describe cómo se imagina al matrimonio Eliot tras las impresiones extraídas de una conversación con el poeta de origen estadounidense: «Pero qué estampa de la desgracia -imaginaria, pero también real. Viven con el pie encima de un taburete, todo el día en la cama; Tom apresurándose a volver a casa por miedo a que ella le riña; he aquí al genio. Eso es lo que deduje de la conversación que tuvimos ayer por la mañana por teléfono» (Woolf, 1941a: 137).

Como ésta, muchas otras imágenes o fantasías anotadas comenzaban a acumularse en su mente y algunas de ellas finalmente acababan por trasladarse a sus libros o artículos periodísticos. En otras ocasiones, personajes retratados a vuela pluma, paulatinamente iban evolucionando hasta transfigurarse en tipos literarios sobre los que empezaría a meditar de manera aislada, ajenos a la persona en que se había basado para crear dicho personaje.

Este proceso, usualmente iniciado en el mundo real, se alejaba, guiado por la imaginación, hasta adentrarse en el vasto espacio de lo irreal. Aquello que abunda en los Diarios es, precisamente, un buen número de historias esbozadas candidatas a formar parte del entramado de una novela. Una buena parte de estos proyectos quedaron sin realizar, cosa natural dado que en muchas ocasiones hacía referencia a escribir sobre un tema determinado y al instante siguiente ya estaba pensando en una idea completamente diferente dejándola tan solo planteada en el diario por si algún día con falta de lucidez mental tenía que recurrir a ella. Sobre este último aspecto anota en septiembre de 1927: «Miles de cosas que escribir, sólo con que tuviera el tiempo y la capacidad de hacerlo. 
Mi capacidad de escribir se agota enseguida. ¡Pero si se me ocurren más libros de los que podré escribir toda mi vida!» (Woolf, 1941a: 104).

Queda claro el fuerte nexo, a veces difícil de diferenciar, que para Virginia Woolf existía entre la realidad y la fantasía. No fueron pocas las amistades que fueron inmortalizadas en sus novelas ni aquella gente anónima que, ignorándolo, quedó reflejada con unas particularidades enteramente distintas a su persona real. Valga como ejemplo recordar que en cierta ocasión Virginia Woolf debió ver el nombre de la novelista Berta Ruck en algún periódico o libro. Tiempo después, al escribir El cuarto de Jacob, decidió usar ese mismo nombre sin percatarse de que ese apelativo no era creación suya. En la ficción, la Sra. Ruck muere. Al poco tiempo le llegó una citación judicial de la verdadera Berta Ruck, que, no obstante, tras una reunión con la escritora, retiró en tanto que había comenzado lo que sería una duradera amistad.

En cuanto a la aparición de textos íntegros, ya elaborados, en el interior de sus Diarios, nada observaremos exceptuando aquel momento en que Woolf confundió sus cuadernos y escribió en su diario aquello que debiera haber redactado en una libreta diferente. A este hecho hace alusión con las siguientes palabras, «Por error, he escrito unas cuantas páginas del Roger aquí, lo cual es demostración, si es que hace falta demostrarlo, como suelo decir, de que me he armado un lío con mis libros» (Woolf, 2003: 364).

Con todo lo comentado, queda claro que, pese a no encontrar apenas extractos literales que posteriormente quedasen impresos en las páginas de sus novelas, podemos hallar una buena cantidad de notas que formarían parte del desarrollo originario de prácticamente todas sus obras. Por otra parte, la referencia que hace sobre el estado de sus escritos en el momento en que redacta los anales se da de modo frecuente en ella. Siguiendo sus páginas día a día se obtiene un claro reflejo del momento creativo en que se encuentra inmersa. Por esta razón, en adición al valor literario y biográfico, los Diarios contienen una gran cantidad de información de notable utilidad para el interesado en estudiar el proceso creativo de la escritora londinense y, de ese modo, comprender sus obras con mayor profundidad: «No se conocen las obras de arte cuando se ven acabadas; hay que haberlas visto también en su proceso de elaboración» (Zweig, 1943: 216).

\section{Crítica y creación}

Por lo general, la gran mayoría de la gente es permeable a la valoración que alguien pueda manifestar sobre su trabajo, más aún si éste se muestra indisolublemente adherido a la vida. Si a esto le añadimos, como es el caso, que esta labor se realiza a lo 
largo de meses, años, de toda una vida, lo extraño sería que uno no se viese afectado ante opiniones ajenas, sobre todo si lo comentado va a recogerse en periódicos o revistas.

El artista tiene la particularidad de trabajar suspendido en el abismo, resultándole imposible saber si el resultado de su tarea va a ser comprendido o no por sus posibles destinatarios. Únicamente él puede y debe confiar en sí mismo; una palabra de ánimo o de reproche puede afectarle, pero su deber personal es continuar avanzando por su inseguro camino. Nadie podrá afirmarle con total certeza si la dirección que sigue es la correcta. Camina a ciegas. Incluso, una vez concluida su realización, ni tan siquiera la aprobación pública puede servirle de baremo; es más, generalmente la gran obra de arte se eleva tan por encima de la mayoría de las mentes que es difícil que resulte comprendida hasta contar con la debida perspectiva. Este hecho en ocasiones incluso supone que nada puede significar el aplauso ajeno salvo la certeza de haber realizado un producto de masas. Trabajar día y noche hasta la extenuación durante años con el conocimiento de que la tarea en cuestión puede ser un fracaso constituye una situación difícil de soportar, sin embargo, creativamente no resulta menos peligroso el saber con certeza que aquello que se realiza contará con el constante apoyo exterior.

Kierkegaard, en su obra Temor y temblor, utiliza un ejemplo bíblico para señalar que la validez de la tarea, su heroicidad, radica en iniciarla y continuarla hasta el final más allá del resultado obtenido. En ocasiones ese resultado jamás llega o se alcanza póstumamente. Es el caso de Kafka. Cuanto más innovadora resulte una obra, siempre que realmente tenga valor y calidad artística, más tiempo tardará en ser reconocida. Su luminosidad, como ocurre con la desplegada por las estrellas, necesita de un periodo de años hasta que puede ser observada.

El artista que pretende innovar, como ocurre en ciertas novelas de Virginia Woolf o se observa en determinados aspectos de la obra del autor checo, corre aún mayor riesgo de ser incomprendido. Virginia Woolf, además de tener su propia imprenta así como el respaldo de un círculo de amigos de notable influencia, no encontró demasiados problemas en compaginar una literatura asequible con otra más complicada. Gide, por su parte, además de resultar más comprensible al lector, tenía al igual que Woolf su propia editorial, su círculo íntimo, además de una excelente salud económica. Kafka estaba solo.

\section{1. André Gide}

André Gide siempre trató de mantenerse al margen de toda crítica, ya fuese periodística o aquella procedente de sectores aislados de la sociedad. Era consciente que 
pese al lenguaje ortodoxo y claro de sus escritos, los temas a los que solía hacer referencia habrían de causar un gran revuelo y poca aceptación entre los lectores ${ }^{9}$. A pesar de ello, existe una paradoja en lo referente a este aspecto, pues pese a no dejarse influir por los comentarios que sobre él pudiesen descargarse, la mayor parte de su obra consiste en un tremendo acto de sinceridad en ocasiones encaminado a defenderse a sí mismo y conseguir la aceptación pública de su personalidad, en especial, aquella procedente del juicio de su prima y mujer Madeleine. Esto último no lo pudo conseguir.

El Diario, de entre todos sus escritos, constituye el ámbito en el que el autor desea con mayor fervor manifestarse plenamente tal y como es. Su primera intención consistió en comentar sus valores morales, sus ideas políticas y religiosas, así como su sexualidad. Uno de los temas que más le preocupó fue el relativo a la máscara que adoptan las personas y que tuvo que utilizar él mismo en una primera época de su vida: «"Si usted quisiera resumir de antemano su obra en una sola frase, ¿cuál sería?" Articulé con voz velada: "Todos debemos representar un papel”» (Gide, 1924: 257). A Gide le obsesionaba la doble moral, la manifestación de diferentes personalidades según una persona se encontrase en uno u otro ámbito. Con el fin de deshacerse personalmente de esta impostura, Gide adoptó una determinación heroica al tiempo que trágica, actitud que desembocaría en una sinceridad que dio pie a numerosos reproches realizados tanto contra sus escritos como contra él mismo. Este cualidad, la honestidad, cobra aún mayor importancia si tenemos en cuenta la época en la que se desarrollaron la mayor parte de las obras de Gide: un periodo histórico devastado por la pérdida de valores y por la falta de una libertad que tantos quebraderos le causó a lo largo de toda su vida.

Además de servirse a sí mismo, Gide fue un escritor comprometido con sus ideas, lo que le requirió el deber de situarse por encima de las opiniones adversas. No obstante, era consciente de que en estos casos las iras ajenas solían responder no tanto a razones artísticas como ideológicas; es decir, aquello que se le reprochaba atendía a determinadas cuestiones morales, pero no a su talento narrativo.

En relación a este aspecto, como ya hemos mencionado, el desprecio ajeno no le preocuparía tanto a Gide como la necesidad de aceptación de sus múltiples contradicciones por parte de su prima Madeleine. Gide buscó en ella a una madre. El amor que sentía por esta mujer era filial, no habiendo en él cabida para la atracción sexual. En su obra autobiográfica Si la semilla no muere, indicará que «Había decidido disociar el placer del amor» (Gide, 1924: 270). Por otra parte, una aceptación íntegra de

\footnotetext{
9 «Las tres cuartas partes de los críticos, y casi todos los de los periódicos, se forman su opinión basándose, no en mis libros por sí mismos, sino en conversaciones de café. Sé por lo demás que no tengo a mi favor ni los cafés, ni los salones, ni los bulevares; y son ellos los que forjan el éxito. De modo que no es ésa la clase de favor que busco, ni he deseado nunca. Dejaré que mis libros elijan pacientemente sus lectores; el pequeño número de hoy forjará la opinión de mañana» (Gide, 1951: 258-259).
} 
su persona por parte de su mujer le liberaría al fin de su más pesarosa preocupación. Gide pertenecía a una elite social que le permitía vivir de modo despreocupado sin agobiarse en absoluto por el dinero recibido de las ventas de sus obras. Además, contaba con un séquito de amigos y conocidos que le consideraban una persona muy respetable. Viajó allá por donde quiso y fue recibido por importantes figuras tanto del ámbito literario como de la política. Por si fuera poco, tenía a su disposición su propia revista, la Nouvelle Revue Française, donde podía publicar lo que creyese conveniente, así como una editorial que había germinado de esa misma revista a través de la cual podía dar a conocer sus obras por provocativas que fuesen.

Con el transcurrir de los años y la publicación de exitosos escritos, Gide llegó a un punto en el que nadie discutía que se tratase de un auténtico talento. Menos aún sus propios colegas literatos. Esto le supuso la concesión del premio internacional más importante de literatura, al menos el más respetado por la opinión pública, el Nobel, que le fue concedido en 1941, cuando se encaminaba hacia su septuagésimo segundo año de vida. Sin embargo, esto no supuso que aquellos que acusaban a Gide de inmoral cambiasen su parecer. La respuesta del autor a estas críticas no se hizo esperar y afirmó que renegaría del Nobel antes que de alguno de sus libros. Por último, cabe destacar que al morir el autor, la Iglesia integró toda su obra en su Índice de libros prohibidos.

\section{2. Franz Kafka}

Con Kafka nos situamos ante un caso claramente diferente tanto al de André Gide como al de Virginia Woolf. Poco dice Kafka en sus Diarios respecto a la carencia de reconocimiento que hubo de soportar a lo largo el conjunto de su vida. Sí que se observan entre sus páginas, en cambio, multitud de referencias a la propia valoración: «Paralización casi total de mi trabajo. Lo escrito no parece tener vida propia, sino que parece el reflejo de trabajos anteriores de mejor calidad» (Kafka, 1937: 276).

El autor de El castillo apenas hace referencia a la voluntad de publicar sus obras; es más, en un primer momento se negaría a hacerlo obviando las continuas peticiones y ofertas realizadas por personas cercanas como es el caso de su íntimo amigo Max Brod. En alguna ocasión, cuando al fin se dejó convencer, los quebraderos de cabeza que le supusieron sus publicaciones resultaron más que evidentes ${ }^{10}$.

\footnotetext{
${ }^{10}$ Brod, en su biografía, recuerda que «Hacía mucho tiempo que ardía en mí el deseo de ver publicado un libro de mi amigo. Franz se mantenía vacilante respecto a este deseo. A veces quería; a veces, no. Por momentos era más fuerte su rechazo; ello sucedía cuando, de vuelta a Praga, debía ponerse a seleccionar del conjunto de sus manuscritos, es decir, de sus Diarios, aquellos pequeños trozos en prosa que consideraba maduros para la imprenta, y hacerles el último retoque, lo que no sucedía sin grandes reconsideraciones, consultas en el Grimm y desesperación. Y entonces se mostraba lo bastante reacio para hallar que todo lo que había escrito era malo; según él, la reunión en libro de sus escritos "sin valor" le
} 
Max Brod señala que en un momento en que ambos vieron comprometida su labor creativa debido a la necesidad de buscarse un empleo que les reportase una economía básica, momento en el que resultaba preciso realizar cierta separación entre vida y obra, él -Brod- se decidió, al igual que Kafka, por inclinarse hacia un trabajo en alguna oficina que le permitiese dedicar las tardes a escribir. Más adelante, sin embargo, optó por dedicarse a la crítica teatral y musical y de este modo dejar su anterior trabajo. Kafka, por su parte, consideró que pese a estar capacitado para desarrollar esta última tarea, le supondría, de realizarla, un «envilecimiento de la creación poética» (Brod, 1937: 79). Por esa razón optó por establecer una separación más tajante entre vida y obra y encerrarse en una oficina hasta casi el final de sus días. Esta posición obedecía, sin duda, a la visión sagrada que guardaba en lo relativo al significado de la escritura, «escribir como una oración» (Brod, 1937: 93). Sacralizar la escritura resulta una opción común a artistas cuya vida y obra se muestran unidas y giran en torno a unos ideales que en no pocos casos conducen a una existencia desarraigada. Se trata de poetas que, por lo común, anteponen la labor creativa a su existencia. Así, observamos el empeño que Kafka puso en escribir cada una de sus palabras aunque en un principio no fuesen a ver la luz pública. Es el caso de sus cartas, monumentos de la literatura mundial redactadas con el mismo esmero que cada uno de sus relatos. A esta idealización hace alusión Kafka en numerosas ocasiones. Reflejamos a continuación la breves pero significativa cita que oyó su joven amigo Gustav Janouch en una de sus conversaciones con Kafka: «La poesía siempre es una expedición en busca de la verdad» (Janouch, 1953: 282) ${ }^{11}$. Ante una pretensión tan elevada poco podía importarle una crítica que no fuese la que él mismo se impusiese de cara a abrazar ese ideal.

Sobre la opinión que pudiese tener su familia sobre sus trabajos, poco cabe señalar, de hecho, el autor guardaba con celo sus escritos en un cajón de su escritorio con el fin de que ni sus padres ni sus hermanas pudiesen poner sus ojos sobre ellos. En los Diarios, narra el momento en que tras escribir El fogonero, lee el relato a su familia mientras el padre le mira con cara de repugnancia. Este ejemplo es más bien anecdótico, pues lo que predominaba en él era un mutismo frente a sus escritos. En cambio, sí que reivindicaba una y otra vez, en especial al padre, el que se respetase tanto su labor de escritor como lo que para él implicaba dicha tarea, es decir, la concesión de una primacía absoluta de la obra respecto a otras actividades de su vida, incluida la oficina, su salud, o todo tipo de relaciones personales. Esto suponía un rechazo -nunca

impediría crear obras mejores. Pero yo me mantuve firme» (Brod, 1937: 122).

${ }^{11}$ Estas son las palabras de Kafka en torno a su concepto poético: «La poesía siempre es una expedición en busca de la verdad. La verdad es lo que todo hombre necesita para vivir y que, sin embargo, no puede obtener ni adquirir de nadie. Cada persona tiene que producirla una y otra vez a partir de su propio interior, o de lo contrario dejará de existir. La vida sin verdad no es posible. Quizá la verdad sea la vida misma» (Janouch, 1953: 282-283). 
comprendido en su familia- hacia ciertas labores, horarios y costumbres del hogar paterno: «"O sea que nadie te entiende", dijo mi madre, "probablemente yo también soy para ti una persona extraña, y tu padre. Y sólo queremos tu mal"» (Kafka, 1937: 198).

En lo concerniente a su prometida Felice, tampoco puede decirse que de ella esperase elogios ni que temiese su crítica. Tan solo pretendía una lectura atenta de cada una de sus cartas, cosa que, según Kafka, Felice no llevaba a la práctica. La realidad era que aquello que le pedía a Felice era un auténtico estudio de cada una de las frases que el escritor checo redactaba con un lenguaje en ocasiones un tanto simbólico. Lo que terminó por exasperar a Kafka encuentra su origen en el momento en que le pidió que leyese su relato Contemplación. A esta petición respondió por carta Felice días después, indicando que su libro «permanecía en la mesilla de noche mientras ella devoraba a autores como Lagerlöf o Jacobsen» (Stach, 2002: 292).

Respecto a sus amigos, conforme pasaron los años las ocasiones en que les enseñaba sus escritos se fueron reduciendo considerablemente. Es más, poco a poco optó por ni tan siquiera hacer comentarios sobre cómo iban desarrollándose los trabajos que tenía en ciernes o si había escrito más o menos líneas. Una de aquellas ocasiones en que decidió recitar algún texto y que recogió en sus Diarios, fue motivada por la lectura pública que hizo a finales de septiembre de 1912 ante unos pocos conocidos de su relato La condena ${ }^{12}$. El resultado fue una tremenda emoción procedente de la satisfacción por ver compensado tanto sufrimiento. Brod, en su famoso retrato del autor, señala por su parte que, pese a no rechazar los halagos, no les concedía especial importancia ${ }^{13}$.

Esta escasez de datos hallados en sus anales en torno a las opiniones que le pudiesen llegar acerca de su escritura, cede totalmente, como se ha señalado, ante el temor al juicio de otra persona, él mismo. Ya desde las primeras líneas de sus Diarios tenemos un apunte sobre este hecho: «Al fin, tras cinco meses de mi vida en los que no pude escribir nada que me dejase satisfecho, y que ningún poder me compensara, aunque todos se sintiesen comprometidos a ello» (Kafka, 1937: 9). Esta estremecedora anotación nos deja una idea de aquello que se va a repetir una y otra vez a lo largo de los Diarios y que apunta a una exigencia terrible en lo referente a su labor creadora.

\footnotetext{
${ }^{12}$ Sobre este hecho anotó Kafka: «Ayer, en casa de Baum, leí ante la familia Baum, mis hermanas, la señora del doctor Bloch con dos hijos suyos (uno de ellos voluntario del ejército). Hacia el final, me pasaba la mano, realmente y sin posibilidad de dominarla, por delante de la cara. Tenía lágrimas en los ojos. Lo indudable de la narración se confirmó» (Kafka, 1937: 183).

${ }^{13}$ «Él también sentía por momentos la alegría del éxito literario. Las más de las veces acompañaba a dicha alegría un quieto sonreír. Pero en una oportunidad lo vi muy enojado por una crítica desfavorable e incomprensiva que se le había hecho a uno de sus libros en el almanaque de la Liga Durero. En general, sus preocupaciones y esperanzas apuntaban a objetos muy distintos del de la resonancia literaria; no es que le resultara precisamente desagradable, pero sí secundaria; no le interesaba mucho la publicidad, ni incidía sobre su sentimiento; de allí que su resistencia a la publicación (excepción hecha de ciertos periodos posteriores de su vida) no fuera muy intensa» (Brod, 1937: 64).
} 
Unas líneas más abajo alude a su: «incapacidad de escribir» (Kafka, 1937: 9). Continuamente Kafka se tenía que rendir cuentas a sí mismo y pocas veces la balanza se inclinó de su lado. Este suplicio era una obsesión que le carcomía día y noche y que solo en la última etapa de su vida, cuando convivió con Dora Diamant y con su enfermedad pulmonar, pudo dejar algo de lado. Sobre su creación más conocida, $L a$ metamorfosis, la valoración que hizo es la siguiente: «Gran aversión hacia La metamorfosis. Final ilegible. Defectuoso casi en su misma raíz» (Kafka, 1937: 221).

\section{3. Virginia Woolf}

«Lo malo de la literatura es que uno depende en exceso de los elogios» (Woolf, 2003: 33), escribió Virginia Woolf el doce de mayo de 1919. La autora londinense era una persona hipersensible a la crítica, por lo que resulta lógico que muchos de los pensamientos mostrados en sus Diarios giren en torno a este tema. Ella misma constantemente realizaba anotaciones sobre el resultado de la novela que estaba escribiendo en un momento determinado. En muchas de esas ocasiones quedaba patente que su opinión acerca de un determinado libro variaba ampliamente según los comentarios que alguien manifestase al respecto.

Por lo general, mientras se encontraba en plena creación de una obra, las dudas sobre la calidad literaria de sus textos no iban más allá de la mostrada por muchos otros escritores inseguros respecto de su valía. El problema real llegaba en el momento en que concluía su trabajo. Tras la alegría producida por haberlo finalizado, Virginia Woolf se sometía a un primer examen, el de su marido Leonard. Leonard Woolf era un excelente crítico literario, había realizado reseñas de multitud de libros y estaba acostumbrado a valorar obras como consecuencia de la fundación entre él y su esposa de la Hogarth Press. Por lo general, era Leonard quien decidía sobre la publicación o no de los escritos que les iban llegando. En lo concerniente a ensayos, libros de historia u otros textos no muy literarios, la decisión era exclusivamente suya. Sin embargo, cuando estaban ante un género más artístico como una novela o un poemario, la decisión corría a cargo de ambos. Lo que parece claro es que tenía un olfato especial tanto para detectar errores como para dar con una rápida lectura con los aspectos más notables de cada libro. Virginia Woolf lo sabía y por lo tanto respetaba bastante su opinión. Normalmente, el estado de nerviosismo de la escritora se acrecentaba a medida que llegaba el momento en que Leonard debía ejercer su juicio crítico, por lo que durante esos periodos arrastraba cierta tendencia a mostrarse pesimista en lo relativo a la valoración de su propio trabajo. Leonard, consciente de la debilidad emocional de su mujer, solía leerse el manuscrito de un día para otro aun tratándose de obras extensas o complicadas como Las olas. De este modo, mientras Virginia Woolf pasaba tanto el día como la noche 
preocupada por el veredicto, su marido se mantenía en vela mientras leía y valoraba con objetividad el resultado de su trabajo. Esta rapidez en el proceso era un verdadero alivio para Virginia Woolf, que por lo general ya conocía la opinión de Leonard a la mañana siguiente.

En cuanto a la sinceridad de su esposo como crítico, no hay motivos para ponerla en duda. Él mismo dejó claro en sus Memorias que tan solo una vez en su vida había engañado a su mujer. Fue a la hora de valorar Los años, su novela menos lograda de acuerdo con su opinión. Virginia Woolf sospechaba que era un rotundo fracaso: «Dirán que ahora ya nadie puede tomar en serio a la señora Woolf [...] que es un libro fatigado» (Woolf, 2003: 332); aun así, le dejó los folios a Leonard con la esperanza de que su juicio fuese algo más positivo que el suyo propio. En aquellos momentos, la primavera de 1937, la escritora atravesaba una profunda inestabilidad emocional. Leonard, preocupado, abrió el diario de Virginia Woolf y tras comprobar la trascendencia de la opinión que le diese a su mujer, decidió engañarla y mostrar su satisfacción por el resultado de dicha novela. «Sabía que se desesperaría y que sufriría una grave depresión nerviosa si mi veredicto no era totalmente favorable [...] Le hablé a Virginia Woolf del libro mucho mejor de lo que en realidad pensaba» (Forrester, 1973: 110-111). En sus Memorias aparece la verdadera impresión que le había causado esta novela: «Las dos partes del libro no encajaban artísticamente y permitían que el dominio de los hechos la controlara con excesivo apremio, por lo que el libro resultaba desigual y no conseguía vivir como una unidad» (Woolf, 1975: 53). Pese a que las dudas de Virginia Woolf no acabaron en ese momento, el posterior éxito de ventas así como la complacencia mostrada por los críticos en los diferentes periódicos y revistas, acabó por convencerla sobre la valía literaria de su obra. Por lo común, tal y como hemos visto, Leonard solía aclamar la mayoría de las obras que Virginia Woolf escribía, demostrando, no casualmente, un especial interés por aquellas cuyo resultado artístico se ha fortalecido con el paso de los años: Las olas, La señora Dalloway, Orlando o Al faro.

Una vez conocida la opinión de Leonard, si no había algún aspecto que Virginia Woolf decidiese modificar, se procedía a la impresión de los ejemplares, que pronto pasaban a ser publicados. A continuación, en cuanto salían los primeros volúmenes, Virginia Woolf enviaba una copia a sus amigos más cercanos. De entre todos, le interesaba especialmente la valoración de una persona, el escritor E. Morgan Forster. Virginia Woolf lo consideraba además de un gran escritor, un crítico genial. Estos nuevos lectores tardaban más tiempo en hacer saber a Virginia Woolf su impresión personal. Dicha tardanza, por desgracia, le suponía un gran desorden y preocupación que se sumaba a la ya de por sí molesta propensión a enfermar al término de cada una 
de sus obras. No obstante, más allá de sus miedos, a la hora de la verdad aguantaba más o menos bien las críticas, siempre y cuando contase al menos con el beneplácito, y si es posible el elogio, de Forster. Su hermana Vanessa era otra de las personas cuya aprobación aguardaba con especial interés, aunque en este caso se debía a motivos emocionales más que literarios.

El siguiente paso en esta ardua tarea consistía en revisar las reseñas que iban apareciendo a través de la prensa y las revistas. Virginia Woolf sabía bien que los comentarios que se hiciesen acerca de sus libros influirían notablemente en el número de ventas y con ello en su economía, un tema que le preocupó a lo largo de toda su vida. Los Diarios están repletos de alusiones a aquel estado de tensión mantenido mientras permanecía a la espera de las distintas recesiones. De todas las críticas posibles, la ejercida por los medios escritos era sin lugar a dudas la que más temor le provocaba. Con varios días de antelación a la publicación de las principales revistas se tornaba intranquila y dubitativa respecto al resultado logrado; a diario acudía a la biblioteca municipal con el fin de comprobar todos aquellos periódicos que pudiesen ofrecerle alguna noticia, al tiempo que se daba ánimos a sí misma tratando de autoconvencerse de que apareciese lo que apareciese sería fuerte y no le afectaría en absoluto. Pero nada de eso era real, nada salvo el temor al fracaso, a no verse reconocida por un público que acataría en buena medida lo que dictasen The Times o The Spectator. De este modo, según se acercaba el momento crítico, su insomnio se volvía más y más insoportable y se aferraba entonces a algo palpable y seguro como era su diario. En él se observa perfectamente cada uno de estos periodos en los cuales sus nervios se estremecen más y más de modo gradual hasta que, una vez leídas las principales reseñas, aceptaba con gusto o con disgusto, pero ya con cierta relajación, el resultado de su trabajo. Respecto a este estado de angustia podemos leer el siguiente comentario realizado en las páginas correspondientes al año 1937: «Al disponerme a subir la escalera aparto la vista, porque ahí están todos los ejemplares de Los años, empaquetados y en trance de serlo, destinados a los críticos. Este es mi último fin de semana de relativa paz» (Woolf, 2003: 331).

La forma que tenía de luchar más efectivamente contra todos estos fantasmas consistía en acudir a su refugio personal, la escritura. El proceso creativo constituía el modo más seguro de salir de la realidad sin que por ello peligrase su débil salud mental. De hecho, frente a un mundo hostil, frente a su extrema sensibilidad, comprendía la realización artística como la creación de un marco protector, un espacio alejado de todo cuanto pudiese perturbarla. El mayor peligro de que se rompiese su estabilidad psíquica se producía, por lo tanto, cada vez que acababa una de sus novelas. 
Todo este miedo a ser criticada, a que no se reconociese su trabajo, originaba que apenas comentase nada a sus allegados antes de que sus obras se hubiesen publicado; de ahí otra de las razones del uso de un diario como válvula de escape. Exceptuando el obligado análisis crítico por parte de Leonard, tan solo una vez dejó que alguien leyese una novela sin que hubiese sido ya editada. Ocurrió en 1925. Durante el invierno de aquel año su amigo Jacques Raverat había caído gravemente enfermo. Virginia Woolf mantenía con él una relación epistolar, pues éste vivía en Francia. Tras conocer su estado de su salud, la escritora decidió enviarle las galeradas de La señora Dalloway, algo que nunca había realizado antes ni volvió a repetir tras esta ocasión. Un mes más tarde Raverat murió.

\section{Afinidades}

Resulta curioso comprobar cómo las relaciones personales que los autores van a establecer entre sí acaban formando, por muy lejos que se encuentren unos de otros y por muy contrarias que se muestren sus posiciones ideológicas, artísticas o morales, una tela de araña en la que todos ellos van a interrelacionarse de forma más o menos estrecha. Estos lazos van a permitirnos tener una idea aproximada de la situación de la literatura europea en un momento determinado. Por estas razones, parece interesante centrarse en algunos de estos encuentros que, al igual que las nubes, desprenden tras su fricción una colosal cantidad de energía. Como añadido, si se profundiza en estos tratos resulta posible hallar episodios concretos de los que posteriormente surgirá una novela, e incluso observar el modo en el que una determinada obra va de la mano de la vida de su autor o, por el contrario, el artista se desliga de su obra de tal forma que surgen bellas creaciones de seres detestables o trabajos amorales de personas que no lo son. Por lo tanto, a pesar de que lo realmente interesante en los escritores lo constituyen, claro está, sus realizaciones, en ocasiones resulta necesario conocer primero al autor para disfrutar más -o menos- de su legado artístico.

\section{1. André Gide}

La lista de personas afines a la literatura que conoció Gide se extiende amplia y variada. Allá por donde viajó -y lo hizo por toda Europa-, llamaba la atención de las principales personalidades del país en cuestión. Representativos artistas, políticos, o gente de diversos ámbitos, se mostraron interesados en mantener una charla con el autor francés. El Diario de Gide recoge muchos de estos encuentros, desde su temprana amistad con Pierre Louÿs o Léon Blum en tiempos de instituto, hasta la visita realizada 
a la Unión Soviética junto a otros afamados escritores, pasando por un corto pero interesante encuentro con Wilde en Argel.

Como acabamos de comentar, ya en su época de estudiante en la Escuela Alsaciana entabló una profunda amistad con el poeta en ciernes Pierre Louÿs. Por aquella época, Gide aún no se tomaba en serio la actividad de escribir, situación de la que se lamentaba en la página del Diario en la que hace la primera alusión a su nuevo amigo: «Él tiene el valor de escribir y yo no me atrevo» (Gide, 1951: 64). Gide tenía tan solo dieciocho años. Uno después manifestaba sentirse celoso, pues «ver que Louÿs está impreso es ver que yo habría podido estarlo y eso ha sido para mí un golpe» (Gide, 1951: 67). En otoño, junto al mismo Pierre Louÿs y algún otro compañero, comenzó a asistir a cenáculos literarios. Fue allí donde conoció a Léon Blum. Aunque estas reuniones no tuvieron éxito y pronto concluyeron, Louÿs y Gide siguieron conservando su amistad y su pasión literaria. Junto a Louÿs, visitó a Paul Verlaine en el hospital en 1890. Ese mismo año, a través del mismo amigo, conoció a Paul Valéry, cuya amistad conservaría durante el resto de sus días. En 1891 empezó a acudir a las veladas artísticas de la calle Rome, donde como es sabido recibía Mallarmé todos los martes. Sus compañías literarias siguieron incrementándose cuando le presentaron al poeta belga Maurice Maeterlinck. Como colofón a ese fructífero periodo de relaciones, a finales de ese mismo año pudo acercarse al celebérrimo Oscar Wilde a través de un conocido común de orientación simbolista, Henri de Régnier. De su persona, el primer día de enero de 1892 indicó: «Wilde no me ha hecho, creo, más que daño. Con él, desaprendí a pensar» (Gide, 1951: 91). Pese a algunas reticencias respecto a la forma de ser del poeta irlandés, al que fundamentalmente le criticaba resultar demasiado afectado y dárselas constantemente de ingenioso, ambos se respetaban y admiraban mutuamente, tanto en el terreno personal como en el artístico. Tiempo después anotaría: «Oscar Wilde es el único poeta moderno que me haya interesado como otra cosa que como autor de versos» (Gide, 1951: 100).

En 1895, tras casarse con Madeleine, realizó un largo viaje que le llevó entre otros destinos a Italia, donde conoció al excéntrico Gabriele d'Annunzio, al que le reprochó «preocuparse mucho por su personaje» (Gide, 1951: 99). En 1897 entabló amistad con Henri Ghéon. Esta relación, en la que ambos compartían tanto gustos literarios como su pasión por jóvenes efebos, acabaría en 1915 tras la conversión de Ghéon al catolicismo. A comienzos de siglo le presentaron al también converso Paul Claudel. Éste, a diferencia de Ghéon, ya había dado "el paso" en la época en que se inició su amistad, 1905. Sobre ello anotó Gide: «"Pero, Gide, entonces, ¿por qué no se convierte usted?...", le dejé ver hasta qué punto sus palabras me perturbaban el espíritu [...] Al marcharse me dejó la dirección de su confesor»(Gide, 1951: 134). Siguiendo con la 
lista de conversos, en 1907 fue visitado por Giovani Papini, cuya relación finalizó en 1920 por la misma razón por la que rompió con Ghéon. No obstante, el grado de amistad que alcanzó con el escritor italiano no es comparable al lazo que le unió a Ghéon; Papini ni tan siquiera le provocó especial interés tras un primer contacto: «Un poco demasiado petulante... Demasiado halagador... Cree demasiado en su propia importancia» (Gide, 1951: 140). Algo parecido debió sentir tras establecer sus primeras conversaciones con Maurice Barrès, de quien anotó: «Se preocupa mucho de su personaje; sabe guardar silencio a fin de no decir nada que no sea importante» (Gide, 1951: 160).

En esta primera década de siglo, su amigo Lord Harry Kessler le puso en contacto con Hofmannsthal, quien le generó desde el primer instante una gran simpatía e interés debido al gusto exquisito que traslucía tanto a través de su obra como a través de su forma de ser. Lo mismo le ocurriría tras tener la oportunidad de acercarse, tres años después, a Rainer Maria Rilke. Éste había quedado deslumbrado por El regreso del hijo pródigo, obra que él mismo se encargó de traducir al alemán en 1914. Gide, a su vez, había editado con anterioridad varios fragmentos vertidos al francés de Los cuadernos de Malte Laurids Brigge.

Además, ya antes del inicio de la contienda europea tuvo ocasión de tratar a varios autores de prestigio mundial como Joseph Conrad, Arnold Bennett, Jean Cocteau y Roger Martin du Gard, con quien mantuvo la amistad de por vida.

En 1912 le ocurrió un acontecimiento similar al que años después viviría Virginia Woolf con motivo de la publicación de Ulises. En este caso, la novela desestimada por la Nouvelle Revue Française sería Por el camino de Swann, primer volumen de la inconclusa serie En busca del tiempo perdido. Su autor, Marcel Proust, no cesó en su tesón por dar a conocer su monumental obra y en 1914 volvió a presentar el manuscrito junto al recién finalizado segundo volumen, A la sombra de las muchachas en flor. Por suerte, Gide rectificó a tiempo y con entusiasmo escribió en enero de 1918: «Maravilloso libro de Proust, que estaba releyendo» (Gide, 1951: 238). Hay que indicar que Proust terminó de corregir las galeradas en 1917, pero como consecuencia de la guerra su novela no se pudo publicar hasta 1919. Esta obra fue una de las más rentables publicaciones de la Nouvelle Revue tanto en términos económicos como artísticos. La relación con Proust la mantendría dentro de lo posible, pues la débil salud que éste padecía le limitaba en extremo su trato con la gente. En mayo de 1921, Gide anotó en un par de entradas una enternecedora descripción de los sufrimientos que soportaba el también escritor parisino, al que tan solo le quedaba un año de vida: «Durante mucho tiempo pude dudar si Proust no usaba un poco su dolencia para proteger su trabajo (lo que me parecía muy legítimo); pero ayer, y ya el otro día, pude convencerme de que 
está realmente muy enfermo. Dice que pasa horas enteras sin mover la cabeza; se pasa todo el día echado, y así varios días seguidos»(Gide, 1951: 256). Pese a ello, como sabemos, Proust no cesó de trabajar en su inmensa obra hasta pocas horas, minutos quizás, antes de morir.

A finales de los veinte y principios de los treinta conoció a otros grandes escritores de los que, según indica en el Diario, quedará gratamente sorprendido. Se trata de sus compatriotas Julien Green, Antoine de Saint-Exupéry, al que vio por última vez tres días antes de su desaparición, Tristan Tzara, Jean Genet, y el Nobel alemán Thomas Mann, a quien dedicó unas líneas en sus anales: «Ambos (Mann y su mujer) me han agradado lo bastante como para desear vivamente verlos. Me parece que se puede hablar con él, sin esfuerzo, de todo y de cualquier cosa» (Gide, 1951: 325).

En 1936 se dirigió con un grupo de autores y hombres de letras en general, entre ellos Louis Aragon, a la URSS. Allí escribió sus Cuadernos de la URSS, que posteriormente integrará en las páginas de su Diario. En ellos anotó con relación al poeta Borís Pasternack, «Nunca hasta entonces había yo experimentado ante nadie una atracción tan súbita y tan singular. Su hermoso rostro, su mirada, su manera de hablar, todo en él respiraba poesía, inteligencia, genio» (Gide, 1951:357). En cuanto a Máximo Gorki, «novelista del pueblo ruso», solo pudo verlo en su lecho de muerte: «Exposición del cuerpo de Gorki en la sala de columnas» (Gide, 1951: 357). Le quedó el consuelo de pronunciar un emotivo discurso durante su funeral, celebrado en la Plaza Roja.

En esta época de entreguerras también estableció contacto con novelistas como André Malraux o Paul Léautaud. Más adelante, ya en plena II Guerra Mundial, conoció a Henri Michaux y a Jean-Paul Sartre, quien veinte años después se atrevió a rechazar el Nobel de literatura debido a motivos ideológicos ${ }^{14}$.

Además de esta extensa lista que se podría aumentar con multitud de autores semidesconocidos, Gide mantuvo contactos con personalidades tan atractivas como los compositores Igor Stravinsky y Darius Milhaud, el cineasta ruso S. M. Eisenstein, el escultor Auguste Rodin, o el general Charles de Gaulle.

\footnotetext{
${ }^{14}$ Sartre, en una entrevista a Radio Canadá, se justificó con las siguientes palabras: «Es evidente que si yo acepto una distinción, por pequeña que sea, si me pongo galones, estaré por encima de los que no poseen ese rango. En ese caso ya no podría hablar en nombre de todo el mundo, porque ya no sería todo el mundo. Eso sí, le aseguro que si me hubieran concedido el Nobel, de Literatura o de lo que fuese, en 1961, en el momento de nuestra lucha contra la guerra de Argelia, lo habría recibido encantado. Hubiera sido un acto político y colectivo y no la glorificación de un hombre» (Caballero, 2005).
} 
Gide, Kafka, Woolf. Iluminación de su vida y obra a través de los diarios

\section{2. Franz Kafka}

El caso de Kafka se presenta opuesto tanto al de André Gide como al de Virginia Woolf. No mantuvo amistad con ninguna de las principales figuras literarias de la época, y a los pocos escritores de cierto renombre que pudo tratar en al menos una ocasión, los conoció, sin involucrarse demasiado, de manera indirecta a través de su amigo Max Brod, quien solía participar con asiduidad en las veladas artísticas. En algún momento Brod animó a Kafka a que tomase parte en alguno de estos encuentros, como así sucedería. Pese a su asistencia, se sabe que en la mayoría de las ocasiones Kafka se mostraba poco participativo. Elias Canetti, en su ensayo sobre Kafka, describe su comportamiento: «Se queja siempre de las dificultades que tiene para hablar, de su enmudecimiento cuando se encuentra entre otras personas, y lo describe con claridad sorprendente: "He pasado una vez más una velada inútil con diferentes personas"» (Canetti, 1969: 61). A estas reuniones, además de Brod, acudían autores como Franz Werfel o Gustav Meyrink, quienes rápidamente se ganaron un puesto a la cabeza del expresionismo.

Uno de los problemas que venían encontrando los escritores checos, obedecía a que el alemán de Praga consistía en una lengua desterritorializada, adecuada exclusivamente para usos menores al no ser la misma que la lengua empleada en Alemania. A ello había que añadirle, además, la condición judía de Kafka, que en lo concerniente a su actividad literaria le suponía una nueva desventaja. Los judíos, minoría en Praga frente a los alemanes, fueron marginados en el uso de su lengua ${ }^{15}$ debido a la fuerte tensión existente en el Imperio Austro-Húngaro entre las diferentes nacionalidades ${ }^{16}$. Esto era algo absolutamente claro y patente en la época en que vivió Kafka, quien tras un primer momento de acercamiento a la cultura judía decidió finalmente optar por la lengua alemana de Praga, la aprendida desde niño en la escuela, pese a la pobreza de vocabulario que esta decisión conllevaba. Sin embargo, el uso de una literatura menor no tiene por qué suponer de por sí una ventaja ni una desventaja. Esta misma particularidad fue la que pudo vivir otro autor contemporáneo a Kafka,

\footnotetext{
${ }^{15}$ Breve explicación del problema de los escritores judíos checos: «¿Cuál es la situación específica de los judíos de Praga en relación con las “cuatro lenguas"? La lengua vernacular, para esos judíos procedentes del medio rural, es el checo, pero el checo tiende a ser olvidado y reprimido; en lo que se refiere al yiddish, éste con frecuencia es despreciado o temido, da miedo, como dice Kafka. El alemán es la lengua vehicular de las ciudades, lengua burocrática de Estado, lengua comercial de intercambio. El mismo alemán, pero esta vez el alemán de Goethe, tiene una función cultural y referencial (y en un segundo plano, el francés). El hebreo como lengua mítica, con el principio del sionismo, está todavía en la condición de sueño activo» (Deleuze y Guattari, 1975: 41).

${ }^{16}$ «La recién nacida Checoslovaquia fue, igual que la difunta monarquía, un estado multinacional, con la influencia decisiva que marcaba el pueblo mayoritario, aunque claro está, bajo otra bandera. Las olas del antisemitismo durante los primeros años de la república no sorprenden tanto, aunque merecen la atención y extrañan por su intensidad, debido a la postura no admisible de tales tendencias por el presidente T. G. Masaryk, muy estimado por la mayoría del pueblo checoslovaco» (Salfellner, 1998: 129).
} 
James Joyce, quien, en cambio, aun soportando las condiciones de una literatura menor, logró operar con exuberancia además de realizar todas las reterritorializaciones posibles.

Por otra parte, no se puede recurrir a la excusa de que Kafka residiese la mayor parte de su vida en Praga para explicar la falta de contacto con otros literatos o lo tardío de su reconocimiento público. Lo único demostrable es que ni tan siquiera en su ciudad natal tuvo profundas amistades, sobre todo desde el momento en que comenzó a centrarse obsesivamente en la creación literaria. Según Brod, este aislamiento «Lo necesitaba Kafka para crear su obra; necesitaba en alto grado de una inmersión en sí mismo; una simple conversación podía llegar a veces a perturbarlo» (Brod, 1937: 94).

Sorprendentemente, pese a ese deseo de soledad y la escasa repercusión en vida que tuvieron sus obras, al menos se sabe de dos autores de primer orden que estimaban a Kafka al tiempo que éste era consciente de dicha admiración. Uno de ellos era R. M. Rilke, quien admiraba el relato El fogonero aun más que La metamorfosis y En la colonia penitenciaria. El otro, Musil, quien había invitado por carta a Kafka a que le enviase alguna narración con el propósito de proceder a su publicación. Pese al interés despertado, Kafka no llegó a satisfacer al autor austriaco.

\section{3. Virginia Woolf}

La relación que tuvo la escritora londinense a lo largo de toda su vida tanto con literatos como con ciertas celebridades de diferentes campos comprende una larga lista de nombres. Algunos de ellos cuentan con reconocimiento mundial, mientras que otros muchos no pasaron de ser conocidos tan solo en un reducido ámbito local. Virginia Woolf, a través de sus hermanos, tuvo la oportunidad de formar parte del conocido Grupo de Bloomsbury, del cual acabó siendo una de sus más eminentes figuras. Por otra parte, a algunos de los mejores escritores del siglo XX los pudo llegar a conocer como consecuencia de su labor como editora en la Hogarth Press. Por si fuese poco, dado que durante muchos años la novelista se encargó de realizar recensiones para The Times, tuvo oportunidad de tratar a una enorme cantidad de célebres autores o artistas de ámbitos variados.

En cuanto al Grupo de Bloomsbury, Virginia Woolf no suele realizar comentarios en sus Diarios como si de un conjunto agrupado o una generación se tratase, sino que en la mayoría de las ocasiones se suele referir a cada uno de sus integrantes de forma aislada. Mientras que con algunos de ellos mantuvo una estrecha amistad a lo largo de toda su vida, con otros perdió el contacto en cuanto el grupo sufrió su primera ruptura. De todo el conjunto de individuos que pasaron por Bloomsbury, solo unos pocos se 
dedicaron a la literatura, mientras otros destacaron en ámbitos como la pintura, la crítica artística, la economía o la política.

Antes de centrarnos en los comentarios que Virginia Woolf hace del grupo en sus Diarios, se torna necesario hacer un breve repaso a la historia del grupo.

\section{4. Bloomsbury}

Bloomsbury nació en Cambridge en el año 1899. Allí estudiaron y establecieron una estrecha amistad unos cuantos jóvenes que no tardarían en destacar en diferentes actividades. Sus primeros integrantes fueron Leonard Woolf, escritor, editor y político; Lytton Strachey, crítico artístico al igual que Roger Fry, quien además fue la persona que dio a conocer el Impresionismo en Inglaterra; Desmond McCarthy, crítico literario; James Strachey, psicoanalista que posibilitó el descubrimiento de la obra de Freud en las islas; Maynard Keynes, uno de los economistas, sobra decirlo, más importantes del pasado siglo; Clive Bell, importante crítico y teórico; David Garnett, escritor; Duncan Grant, considerado como el más famoso pintor británico de la generación de entreguerras; Sidney Turner, quien en opinión de muchos fue el más brillante de todos ellos y sin embargo decidió retirarse para pasar a trabajar en hacienda; y, por último, Thoby Stephen, hermano de Virginia Woolf, quien murió antes de que el grupo estuviese consolidado. Este conjunto, cuando salió de Cambridge, continuó sus reuniones en el 46 de Gordon Square, el hogar de los Stephen. De este modo, al grupúsculo original se le unió un elemento londinense al que pertenecían Virginia Woolf y su hermana Vanessa. Esto ocurriría en 1904, tras la muerte de su padre.

En estas reuniones, las dos hermanas eran tratadas de igual a igual respecto del grupo de hombres, algo sorprendente en una sociedad tan tradicional como la inglesa, más si cabe en aquella época de principios de siglo. En 1906, Vanessa se casó con Clive Bell y se creó otro centro de reuniones, pues al de Gordon, donde pasaría a vivir el matrimonio, se le unió el nuevo hogar de Virginia Woolf y su hermano Adrian, situado en Fitzroy Square. Allí se comenzó a reunir la agrupación todos los miércoles. Bloomsbury continuó más o menos unido hasta el inicio de la guerra, en 1914. En ese momento de obligada interrupción se desperdigaron temporalmente sus integrantes. Cuando tras el conflicto se reanudaron las conversaciones, algunos de ellos llevaban ya una vida ajena a la desarrollada hasta entonces. Por otro lado, nuevos componentes se habían integrado a las reuniones, aunque debido a las diversas entradas y salidas que se producían, el grupo quedó algo disperso y era difícil distinguir quién formaba parte de él y quién no. Aun así continuó existiendo un núcleo central, "el viejo Bloomsbury", fiel al cenáculo de principio a fin. Entre este último sector se encontraba Virginia Woolf. 
Los fallecimientos de Lytton Strachey en 1931 y de Roger Fry en 1936, modificaron por completo su configuración, por lo que a mediados de los treinta podemos situar la fecha de defunción del grupo.

Una de las personas que sin llegar a formar parte de ese núcleo fundador siempre fue considerado uno más dentro de Bloomsbury fue E. Morgan Forster. Al margen de su amistad, a la que Virginia Woolf hace múltiples referencias en sus Diarios, uno de los aspectos que más le interesaba de él era la opinión que el escritor tenía sobre sus obras, aspecto que denota una vez más la dependencia de Virginia Woolf respecto de las consideraciones ajenas. Sobre su íntima relación así como respeto profesional, basta con mencionar una cita de enero de 1924 en la que Virginia Woolf se refiere a una carta que le ha enviado Forster: "“¿A quién anunciaré antes que a nadie, si no es a ti [Leonard] y a Virginia Woolf que acabo de escribir las últimas palabras de mi novela [Pasaje a la India]?". Está emocionado, como yo lo estoy siempre en esos casos» (Woolf, 1941a: 14).

Un poeta al que en ocasiones se le ha considerado erróneamente como miembro de Bloomsbury es D. H. Lawrence. Efectivamente, mantuvo contactos con el grupo en ciertas épocas, mas no dejaron de ser breves y tenues, hasta el punto de que en cuanto conoció a algunos de sus miembros no tardó en criticar ciertas actitudes que le disgustaban, como así atestiguó a través de una conocida carta enviada a una amiga cercana tanto a él como a Bloomsbury ${ }^{17}$. En general, aquello que criticaba a sus integrantes apuntaba a su pretensión de «querer resultar en todo momento ingeniosos e inteligentes» (Bell, 1968: 62). No obstante, pese a estos desacuerdos, las relaciones que mantuvo con Virginia Woolf en concreto fueron amistosas y de mutuo respeto en el terreno profesional.

Al margen ya del selecto grupo de Bloomsbury, otro de los escritores con el que Virginia Woolf tuvo una relación cercana fue T. S. Eliot. El quince de noviembre de 1918 anotó en su diario: «Fui interrumpida en algún lugar de esta página al llegar el señor Eliot» (Woolf, 1941a: 145). El motivo de la visita de Eliot obedecía al deseo por parte del poeta de ver publicados a través de la Hogarth Press algunos de sus poemas, lo que logró sin problema alguno. Este encuentro profesional acabó finalmente en una estrecha amistad pese a ciertas divergencias literarias. Una de esas opiniones

17 Carta de Lawrence a su amiga Lady Ottoline Morrell: «Oír a estos jóvenes hablar me llena verdaderamente de una furia negra: hablan sin parar, sin parar, y nunca, nunca dicen algo bueno o real. Su actitud es de lo más irreverente y vocinglera. Viven encastillados, cada uno en su pequeña y dura concha, y aparte de esto dicen palabras. Jamás, ni por un segundo, una salida que demuestre sentimientos, y ninguna reverencia, ni una brizna ni un grano de reverencia. No puedo soportarlo. No toleraré a gente como ésta; preferiría estar solo. Por la noche me hicieron soñar con un escarabajo que picaba como un escorpión. Pero lo maté: era un escarabajo muy grande. Lo arrinconé y se escapó, pero lo agarré de nuevo y lo maté. Es este horror de pululantes personajillos lo que no puedo soportar» (Bell, 1968: 64-65). 
encontradas se produjo en torno a Ulises, obra por la que Eliot sentía un profundo respeto mientras que Virginia Woolf, quien debería dirimir si se publicaba o no, lo consideraba «una obra fallida. A mi juicio, no le falta talento; pero de baja estofa. El libro es difuso. Es enmarañado. Es pretencioso» (Woolf, 2003: 74). Pese a todo, estos rasgos, por sí mismos no eran cualidades positivas ni negativas, motivo por el que Virginia Woolf se dejó convencer tras escuchar las opiniones de ciertos críticos y amigos que alababan la obra. Al cabo de tres semanas, el veintiséis de septiembre de 1922, Virginia Woolf escribió: «El libro será un hito, debido a que destruye toda la literatura del siglo XIX» (Woolf, 2003: 75). A pesar de este cambio de opinión, la reacción llegó tarde y la Hogarth Press no pudo publicar Ulises.

En lo concerniente al resto de visitas que recibía en casa con motivo de las publicaciones en su editorial, en una entrada de abril de ese mismo año, 1922, leemos la impresión que le había causado un Robert Graves a quien compara físicamente con Shelley para, a continuación, señalar que «la convicción de que uno es un genio es un mal asunto»; finalmente sentencia: «No. No creo que vaya a ser un gran poeta» (Woolf, 1941a: 37-38). Aun así, Graves editó sus poemas bajo el sello de la Hogarth Press. También haría lo propio Sigmund Freud con la edición de su obra en inglés. Virginia Woolf visitó al psicólogo poco antes de que éste falleciese en 1939, cuando el eminente doctor ya vivía en Londres. No pudo llegar a tratar, sin embargo, a otro de sus autores, el novelista soviético Máximo Gorki.

H. G. Wells, conocido novelista perteneciente a la generación inmediatamente anterior a Virginia Woolf, fue otra de las personas con quien la autora tuvo ocasión de dialogar. Esta vez fue gracias a las reuniones que su marido Leonard mantenía con diversas personas debido a motivos relacionados con la recientemente creada Sociedad de Naciones. En sus Diarios, hallamos una serie de descripciones y explicaciones al respecto, esta vez sobre cómo en una de esas reuniones le pidió a Wells que le hablase de dos escritores, el poeta T. Hardy, al que ella llegaría a conocer más adelante, y el novelista Henry James, a quien había conocido en su infancia debido a la amistad que éste mantenía con su padre. También a través de estas visitas pudo sostener algunas palabras con Aldous Huxley, a quien comparó por su físico con «un gigantesco saltamontes» (Woolf, 1941a: 72). El mismo día en que conoció a Huxley tuvo la oportunidad de tratar a otro importante novelista inglés, Arnold Bennett. A pesar de que en un primer momento no estaba nada interesada en conseguir la amistad del escritor: «llevarme bien o mal con Bennet me importa un comino» (Woolf, 1941a: 184), ambos trabaron, con el tiempo, una relación bastante cordial que concluyó cinco años después de su primer encuentro, cuando falleció el novelista en 1931. A través de las palabras que escribió en su cuaderno se puede observar el aprecio que llegó a sentir Virginia 
Woolf por su persona: «Arnold Bennet murió anoche; lo cual me ha dejado más triste de lo que hubiera supuesto. Un hombre amable y auténtico; limitado, un tanto torpe en el vivir; con buenas intenciones» (Woolf, 2003: 2012).

A finales del mes de noviembre de 1930 Virginia Woolf disfrutó durante unas horas de la conversación del genial poeta irlandés W. B. Yeats. La intermediaria en esta ocasión fue su amiga Ottoline. Lo que pensó mientras se presentaba ante el poeta lo registró en su diario con estas breves y curiosas palabras: «Ésta es una mano famosa» (Woolf, 1941a: 181). Por aquel momento, el escritor, al que le quedaban nueve años de vida, era ya una figura consagrada que además había recibido el Premio Nobel siete años atrás.

Un nuevo gozo le llegó cuando tuvo la posibilidad de charlar con Thomas Hardy en julio de 1926. El viaje a Dorchester, donde residía el poeta, surgió en parte motivado por la gran admiración que Virginia Woolf sentía por él y en parte porque el suplemento literario de The Times le había pedido que fuese escribiendo un artículo necrológico sobre del autor. Durante este encuentro la novelista se mostró como una discípula ante el maestro; le hizo todo tipo de preguntas acerca de la escritura en general y de la creación poética en particular. Si atendemos a la extensión que Virginia Woolf le dedica a Hardy en sus Diarios, más de tres páginas, se adivina la importancia que tuvo para ella esta visita. Cabe indicar que dos años después acudiría junto a su marido al funeral del poeta, celebrado en la Abadía de Westminster. Esta fecha Virginia Woolf la recordó en su diario sin extenderse, pues en ese momento había algo que le robaba toda su energía: una tremenda depresión acompañada de una jaqueca que apenas le permitía dedicarse a la redacción del capítulo final de Orlando. «Ayer fuimos al funeral de Hardy. ¿En qué pensaba yo? En la carta de Max Beerbohm... Dudo de la capacidad del animal humano para mantener la dignidad en las ceremonias» (Woolf, 1941a: 112).

La poetisa Edith Sitwell fue entre quienes compartían su profesión, una de las personas con la que más llegó a intimar. Su nombre aparece a menudo entre las páginas de la primavera y el verano de 1925. Los elogios hacia ella son numerosos y vienen a expresarse del modo siguiente: «Admiro su obra, y esto es algo que no puedo decir de casi nadie» (Woolf, 1941a: 42). Precisamente fue con Sitwell con quien en junio de ese mismo año acudió a una fiesta para conocer a la famosa escritora estadounidense Gertrude Stein, de quien anotó: «muy imponente» (Woolf, 1941a: 70). Esta visita no fructificó en relación alguna con quien se consideraba "madre adoptiva" de la Generación Perdida.

Por último, cabe destacar que E. M. Forster, a mitad de los años treinta, cuando los regímenes totalitarios amenazaban la paz de Europa, en un par de ocasiones apremió a Virginia Woolf para que asistiese a alguna reunión antifascista. Virginia Woolf, que 
aunque tenía simpatía por la izquierda no estaba muy interesada en temas políticos, declinó la primera invitación, pero cuando un año después, en 1936, Forster le volvió a realizar la petición, accedió a desplazarse hasta París para acudir a un mitin antifascista. El resultado no pudo ser más desalentador, pues fue insultada por muchos de los asistentes, entre los que se encontraba André Gide, quien según cuenta Quentin Bell, la encontraba negligente: «Gide la consideraba poco práctica y es muy posible que fuese así. Virginia Woolf decía: "Gide se mete conmigo". No sé qué habría de cierto en ello, pero me imagino que un comité con Gide y Virginia podía terminar mal» (Forrester, 1973: 83).

\section{Conclusiones}

Con este trabajo hemos pretendido realizar un breve repaso, a través de los diarios, en torno a la integración de determinados aspectos relativos al proceso creativo en la vida de tres de los novelistas más innovadores y de mayor calidad del siglo que dejamos atrás. Las conclusiones extraídas son las expuestas a continuación:

En primer lugar, dado que los autores se encuentran a la hora de realizar los diarios con su herramienta usual de trabajo, el lenguaje, existe una tendencia natural en ellos a trascender la mera anotación de lo que ha sido su día para, de este modo, pasar a invadir su faceta profesional, la literaria. Por este motivo, estas páginas se convierten en un campo de cultivo tremendamente fértil para la germinación de futuras obras. Como valor añadido, nos encontramos con que en este tipo de escritos los autores no deben rendir cuentas ni al lector, ni al editor, ni tan siquiera a ellos mismos -aunque esto último no siempre ocurre-, con lo que logran descargar en buena medida la presión que la escritura de una obra seria tiende a ejercer.

Como ha podido comprobarse, las finalidades y el uso creativo que van a hacer del diario varían en cada uno de los autores estudiados. En el caso de Gide predominó siempre un fin, la sinceridad, al que pronto se le uniría la perspectiva de una futura publicación. Esta particularidad le obligaba a mantener un rigor formal no presentado en los diarios de Kafka o de Woolf. Gide también encontró en estos escritos un filón del que extraer material para sus futuras obras, llegando en ocasiones a transcribir párrafos de modo literal. Este hecho fue posible debido al carácter unitario y biográfico de buena parte de su obra en prosa. Virginia Woolf, sin embargo, aunque no descartó una futura selección de algunas páginas de sus cuadernos con el fin de publicarlas, no les concedió la importancia que otorgaba a otros escritos, por lo que su lenguaje resulta más impreciso, menos riguroso que el del autor francés. Este descuido formal bascula hacia una mayor carga de espontaneidad, algo que Gide no logra reflejar a través de sus 
escritos. Como ya se ha comentado en el capítulo correspondiente, una escritora como Virginia Woolf, tan interesada en describir la realidad aunque posteriormente la moldease a su gusto, poseía en sus diarios una gran cantidad de material bruto del que, tal como hizo, podía valerse para crear nuevos personajes, dibujar atmósferas, paisajes, $\mathrm{y}$, en general, todo lo que le resultase de utilidad para tejer un mundo alrededor de aquello que solía constituir el núcleo de sus novelas: una visión subjetiva de la realidad con elevadas dosis de cuidada emotividad. Estas descripciones tan características de los Diarios de Woolf, encuentran su reverso en el uso que de ellos hacía Kafka. Para el novelista checo, este tipo de anotaciones constituían un instrumento de autoanálisis. En ellos su mirada se dirige hacia el interior, apenas existen visiones objetivas de la realidad. Kafka se muestra como objeto y sujeto a un mismo tiempo. Su mente, su escritura, se consolida tanto como herramienta de estudio como elemento a estudiar, dando forma a una espiral, una obsesión. En este caso, al aparecer todo en su vida tan inexorablemente unido, el uso del diario no es sino un apéndice más de lo que durante el día o la noche se solía manifestar mediante una verbalización, un pensamiento, un sentimiento, o un sueño. El diario le tranquilizaba, pero no le podía salvar mientras no lograse salir de dicha espiral. Entre Kafka y su obra se da una retroalimentación constante. Todo en él permanece interrelacionado. Pese a que es cierto que en aquellos cuadernos marrones se engendraban historias increíbles, resulta evidente que estas narraciones estaban en él, vivían en él. El telar Kafka se emplazaba, en primer lugar, en su interior. Con todo lo explicado resulta prácticamente innecesario comentar que nos encontramos ante unos diarios de uso estrictamente privado.

Respecto al juicio crítico, resulta destacable que por mucho que les pudiese afectar una opinión adversa, todos ellos antepusieron el instinto creador sobre cualquier otra faceta de la vida, por lo que ninguno consintió en modificar sus obras ante coacciones ajenas a su propia valoración. En los tres casos escribir fue una necesidad vital, una prolongación del propio ser, de modo que una crítica contra sus escritos se tornaba a su vez en reproche contra sus vidas. Por este motivo, dichos ataques, cuando se producían, ya procediesen de periódicos, de familiares o amigos, suponían una afrenta personal, hecho que a continuación ocasionaba una autoafirmación ante y mediante la obra literaria. El acto creativo pasaba así a erigirse como instinto de supervivencia. Esta defensa frente al exterior encuentra su contrapeso en el interior de cada uno de estos autores, quienes a través de sus obras van a juzgar sus respectivas vidas de modo que toda crítica externa quedaría erradicada por aquella otra interna que en unas ocasiones resultaba indulgente, tal y como ocurre en el Corydon de Gide, y en otros casos, condenatoria, como sucede en El proceso y en otros muchos escritos de Kafka. 
Este quedar subyugado por el proceso creativo, en el caso de Kafka parece tan evidente que llega a resultar diabólico, pues da la impresión de que el novelista vive su destino para después escribirlo y que, además, ese destino surge como si le fuese dictado por algo ajeno a su conciencia. La impresión que nos queda se manifiesta como un querer ser tan fiel a la obra que ésta ha de ser vivida previamente. Esto ocurrirá incluso en lo concerniente a su propia muerte. Lacan solía comentar que el neurótico no puede confesar lo que no sabe, situación usual y cercana a ciertos personajes dibujados por Kafka, en quienes «Lo absurdo del castigo es tan insoportable que el acusado quiere hallar una justificación a su pena: El castigo busca la falta» (Kundera, 1986: 119).

El elemento trágico de estos escritores, como hemos podido comprobar, dejará su huella en cada uno de sus diarios, pese a que quedará reflejado de modo especialmente patente en el del Franz Kafka. Gide, sin lugar a dudas, mentalmente es el más fuerte de los tres, resultado de esta preeminencia alcanzará el conocido pacto consigo mismo en un viaje a tierras africanas. Virginia Woolf, por absurdo que parezca, pacta con la muerte - cada uno de los tres se salva como buenamente puede-. Ante la cercanía de la locura decide quitarse la vida no sin antes dejar una carta a su marido y otra a su hermana Vanessa ${ }^{18}$ donde expone muy racionalmente la decisión tomada. Frente a esos delirios de escritura en los que actuaba casi como una escribiente, decide evitar ser raptada definitivamente por ese mismo espíritu que a menudo guiaba su mano, el de la locura. Finalmente, a Kafka, sin nada a lo que asirse, sin nada con lo que poder llegar a un acuerdo, no le queda otro remedio que pactar con la literatura, acabando así del mismo modo que hubiese acabado uno de sus personajes. El novelista se convierte en visionario, en poeta. Este halo trágico que se dilata hasta el momento de su muerte, es el

\footnotetext{
${ }^{18}$ Carta de Virginia Woolf a Leonard Woolf: «Querido, estoy segura de que, de nuevo, me vuelvo loca. Creo que no puedo superar otra de aquellas terribles temporadas. No voy a curarme en esta ocasión. He empezado a oír voces y no me puedo concentrar. Por lo tanto, estoy haciendo lo que me parece mejor. Tú me has dado la mayor felicidad posible. Has sido en todo momento todo lo que uno puede ser. No creo que dos personas hayan sido más felices hasta el momento en que sobrevino esta terrible enfermedad. No puedo luchar por más tiempo. Sé que estoy destrozando tu vida, que sin mí podrías trabajar. Y lo harás, lo sé. Te das cuenta, ni siquiera puedo escribir esto correctamente. No puedo leer. Cuanto quiero decir es que te debo toda la felicidad de mi vida. Has sido totalmente paciente conmigo e increíblemente bueno. Quiero decirte...todo el mundo lo sabe. Si alguien podía salvarme, hubieras sido tú. N queda nada en mí salvo la certidumbre de tu bondad. No puedo seguir destrozando tu vida por más tiempo. No creo que dos personas pudieran haber sido más felices de lo que nosotros hemos sido» (cit. en Bell, 1972: 593-594). Carta escrita a su hermana Vanessa: «Querida, no puedes imaginarte lo mucho que me ha gustado tu carta. Pero siento que he ido demasiado lejos en esta ocasión para que pueda volver. Es lo mismo que la primera vez, todo el tiempo oigo voces, y sé que no puedo superar esto ahora. Todo cuanto quiero decir es que Leonard ha sido sorprendentemente bueno cada día, siempre; no puedo pensar que alguien hubiera podido hacer más de lo que ha hecho por mí. Hemos sido perfectamente felices hasta las últimas semanas, cuando este horror comenzó. ¿Harás que esté seguro de esto? Siento que le queda mucho por hacer y que seguirá adelante, mejor sin mí, y que tú le ayudarás. Apenas si puedo pensar con claridad ya. Si pudiera te diría cuánto habéis significado tú y los niños para mí. Creo que lo sabes. He luchado contra esto, pero ya no puedo más» (Woolf, 1975: 107-108).
} 
elemento magnético que suele atraer a casi todos los lectores que se acercan a su obra; el mismo que existe con diferentes gradaciones tanto en Woolf como en Gide.

Concluiremos estas páginas con dos citas de Stefan Zweig extraídas de su ensayo La lucha contra el demonio. Este libro explica con precisión las arduas luchas internas de los artistas que tienen que luchar contra su propio yo; es el caso de nuestros protagonistas, quienes sin lugar a dudas hubiesen comprendido que «ese demonio interior que nos eleva es una fuerza amiga en tanto que logramos dominarlo; su peligro empieza cuando la tensión que desarrolla se convierte en una hipertensión, en una exaltación» (Zweig, 1925: 12), pues «Si la enfermedad puede crear cosas inmortales, ya no es enfermedad, sino que será una fuerza, un exceso de salud» (Zweig, 1925: 23).

\section{Bibliografía}

BELL, Q. (1968): El grupo de Bloomsbury. Madrid, Taurus, 1976. (1972): Virginia Woolf. Barcelona, Debolsillo, 2004.

BROD, M. (1937): Franz Kafka. Una biografía. Madrid, Alianza, 1974.

CABALlERO, O. (2005): "Jean-Paul Sartre. El gran gurú de la izquierda". Leer, 162, pp. 24-33.

CANETTI, E. (1969): El otro proceso de Kafka. Barcelona, Muchnik, 1982.

DELEUZE, G. y GUATTARI, F.( 1975): Kafka. Por una literatura menor. México, Era.

FERIA JALDÓN, E. (2000): Estudios sobre Kafka. Sevilla, Renacimiento.

FORRESTER, V. (1973): Virginia Woolf. El vicio absurdo. Madrid, Ultramar, 1978.

GIDE, A (1902): El inmoralista. Barcelona, Argos Vergara, 1981.

- (1906): Amyntas. Madrid, Guadarrama, 1997. (1914): Los sótanos del Vaticano. Madrid, Alianza, 1985.

(1924): Si la semilla no muere. Madrid, Losada, 2002.

(1924/1951): Corydon/Et nunc manet in te. Madrid, Odisea, 2002.

(1925): Los monederos falsos. Barcelona, Seix Barral, 1985.

(1951): Diario. Barcelona, Trayectos, 1999.

HERRERO QUIRÓS, C. (1996): Virginia Woolf: Proceso creativo y evolución literaria. Valladolid, Universidad de Valladolid.

JANOUCH, G. (1953): Conversaciones con Kafka. Barcelona, Destino, 1997.

JASPERS, K. (1922): Genio artístico y locura. Strindberg y Van Gogh. Barcelona, El Acantilado, 2001.

JUNG, C. G. (1995): Sobre el fenómeno del espíritu en el arte y en la ciencia. Madrid, Trotta, 2002.

KAFKA, F. (1925): El proceso. Madrid, Cátedra, 2004. 
Gide, Kafka, Woolf. Iluminación de su vida y obra a través de los diarios

- (1926): El castillo. Madrid, Cátedra, 1998.

_ (1927): América. Madrid, Alianza, 1995.

(1937): Diarios (1910-1923). Madrid, Lumen, 1995.

(1952): Cartas a Milena. Madrid, Alianza, 2000.

(1992): Cartas a los padres de los años 1922-1924. Barcelona, Ediciones de la Tempestad.

(1999): Padres e hijos. Barcelona, Anagrama.

KIERKEGAARD, S. (1843): Temor y temblor. Madrid, Editora Nacional, 1975.

KUNDERA, M. (1986): El arte de la novela. Barcelona, Tusquets, 2004.

MARTIN DU GARD, R.(1959) : Obras completas. Tomo II. México, Aguilar.

SALFELLNER, H. (1998): Franz Kafka y Praga. Praga, Vitalis, 2003.

STACH, R. (2002): Kafka. Los años de las decisiones. Madrid, Siglo veintiuno de España, 2003.

VAN RYSSELBERGHE, M. (1976): Los cuadernos de la "Petite Dame”. Notas para la historia auténtica de André Gide, Madrid, Alianza.

WOOLF, L. (1975): La muerte de Virginia Woolf. Barcelona, Lumen.

WOOLF, V. (1925): La señora Dalloway. Madrid, Alianza, 2003.

— (1927): Al Faro. Madrid, Cátedra, 1999.

(1928): Orlando. Madrid, Alianza, 2003.

(1929): Un cuarto propio. Madrid, Alianza, 2003.

(1931a): Las Olas. Madrid, Lumen, 2000.

(1931b): Londres. Barcelona, Lumen, 2005.

(1941a): Diario íntimo I, II y III. Barcelona, Grijalbo Mondadori, 1993.

(1941b): Entre actos. Barcelona, Lumen, 1976.

(1941c): Hogarth House 1915-1921. Diarios volumen I. San Lorenzo del Escorial, Libertarias, 1993.

(2003): Diario de una escritora. Madrid, Ediciones y Talleres de Escritura Creativa Fuentetaja.

ZWEIG, S. (1925): La lucha contra el demonio (Hölderlin Kleist, Nietzsche). Barcelona, El Acantilado, 2003.

(1943): Tiempo y mundo. Barcelona, Juventud, 2004. 